\title{
On the role of dauer in the adaptation of nematodes to a parasitic lifestyle
}

\author{
Lieke E. Vlaar ${ }^{1}$, Andre Bertran², Mehran Rahimi', Lemeng Dong ${ }^{1}$, Jan E. Kammenga², Johannes Helder², \\ Aska Goverse $^{2}$ and Harro J. Bouwmeester ${ }^{1 *}$
}

\begin{abstract}
Nematodes are presumably the most abundant Metazoa on Earth, and can even be found in some of the most hostile environments of our planet. Various types of hypobiosis evolved to adapt their life cycles to such harsh environmental conditions. The five most distal major clades of the phylum Nematoda (Clades 8-12), formerly referred to as the Secernentea, contain many economically relevant parasitic nematodes. In this group, a special type of hypobiosis, dauer, has evolved. The dauer signalling pathway, which culminates in the biosynthesis of dafachronic acid (DA), is intensively studied in the free-living nematode Caenorhabditis elegans, and it has been hypothesized that the dauer stage may have been a prerequisite for the evolution of a wide range of parasitic lifestyles among other nematode species. Biosynthesis of DA is not specific for hypobiosis, but if it results in exit of the hypobiotic state, it is one of the main criteria to define certain behaviour as dauer. Within Clades 9 and 10, the involvement of DA has been validated experimentally, and dauer is therefore generally accepted to occur in those clades. However, for other clades, such as Clade 12, this has hardly been explored. In this review, we provide clarity on the nomenclature associated with hypobiosis and dauer across different nematological subfields. We discuss evidence for dauer-like stages in Clades 8 to 12 and support this with a meta-analysis of available genomic data. Furthermore, we discuss indications for a simplified dauer signalling pathway in parasitic nematodes. Finally, we zoom in on the host cues that induce exit from the hypobiotic stage and introduce two hypotheses on how these signals might feed into the dauer signalling pathway for plant-parasitic nematodes. With this work, we contribute to the deeper understanding of the molecular mechanisms underlying hypobiosis in parasitic nematodes. Based on this, novel strategies for the control of parasitic nematodes can be developed.
\end{abstract}

Keywords: Dauer, Parasitic nematodes, Clade 12, Quiescence, Globodera

\section{Background}

Nematodes, also referred to as roundworms, play an important role in many ecosystems, from ocean floors to arable soils. Stemming from a common non-parasitic ancestor, most contemporary nematodes are free-living and trophically diverse. As such, they are represented in all major trophic levels in soil and sediment food webs.

\footnotetext{
*Correspondence: h.j.bouwmeester@uva.nl

1 Plant Hormone Biology Group, Green Life Sciences Cluster,

Swammerdam Institute for Life Sciences, University of Amsterdam, Science Park 904, 1098 XH Amsterdam, The Netherlands

Full list of author information is available at the end of the article
}

Nematodes can be subdivided based on their trophic behaviour. According to this criterion, they can be divided into three groups: free-living, obligate parasitic and facultative parasitic nematodes. The first feed predominantly on microorganisms such as bacteria or fungi and, in the case of predatory free-living nematodes, they devour other nematode species. Obligate parasitic nematodes feed on plant, invertebrate or vertebrate hosts. Facultative parasitic nematodes are usually more flexible in their food source; in a free-living cycle they feed on microbes, whereas in a parasitic cycle they parasitize a host organism [1]. Interestingly, parasitism has evolved original author(s) and the source, provide a link to the Creative Commons licence, and indicate if changes were made. The images or other third party material in this article are included in the article's Creative Commons licence, unless indicated otherwise in a credit line to the material. If material is not included in the article's Creative Commons licence and your intended use is not permitted by statutory regulation or exceeds the permitted use, you will need to obtain permission directly from the copyright holder. To view a copy of this licence, visit http://creativecommons.org/licenses/by/4.0/. The Creative Commons Public Domain Dedication waiver (http://creativeco mmons.org/publicdomain/zero/1.0/) applies to the data made available in this article, unless otherwise stated in a credit line to the data. 
at least 18 times independently within the phylum Nematoda $[2,3]$.

It is estimated that the cost of parasitic diseases caused by nematodes in livestock worldwide reaches into the tens of billions of US dollars annually [4]. In addition, six of the 13 core neglected tropical diseases in humans are caused by nematodes [5]. It is noted that only a numerically very limited subset of these parasitic nematodes is responsible for this damage (e.g. [2]). Control of these nematodes is difficult, and many anthelmintic drugs have become ineffective due to natural selection for resistant populations [6]. In agriculture, plant-parasitic nematodes cause over US\$ 100 billion of losses annually [7]. Until recently, fumigants (general biocides) were massively applied to control plant parasites. They are now largely banned because of their non-specificity and their high toxicity. Hence, a relatively small fraction of parasitic nematodes pose a huge burden on humans, both in terms of health and food safety, and socio-economically.

In order to develop new tools for the control of parasitic nematodes, in humans and animals as well as in agriculture, a better understanding of the mechanisms underlying the parasitic lifestyle is needed. The phylum Nematoda is divided into 12 clades, of which the common ancestor is considered non-parasitic. Up to now, parasitism has been found in Clades 1, 2, 5, and 8 to 12 $[2,3,8,9]$. For the evolution of parasitism in Clades 9 and 10 , it has been hypothesized that a specific type of hypobiosis, called dauer, is critical because it enables the nematode to persist in the temporary absence of food [10]. Specific for dauer is the dauer signalling pathway, which underlies dauer of nematodes in Clades 9 and 10. In this review, we investigate the hypothesis that the dauer pathway was also essential for the evolution of parasitism in Clade 12. To do so, a hybrid definition of dauer is used as a state in which the larva is (i) non-feeding and (ii) essentially non-ageing, and the species has (iii) a conserved dafachronic acid biosynthetic pathway that produces (a chemical analogue of) dafachronic acid. Additional morphological characteristics, such as radial constriction and/or a sealed buccal capsule, the ability to survive some degree of desiccation and the ability to adopt a coiled posture, are characteristic for dauer in some species, but are not ubiquitous. Finally, we discuss the literature on the perception of host cues and their probable integration into the dauer signalling pathway.

\section{Hypobiosis in nematodes}

Hypobiosis, or developmental arrest, is a state of reduced metabolic activity and exists in two different forms: cryptobiosis and dormancy (Fig. 1). Cryptobiosis, or anabiosis, is more extreme in that organisms in this state show almost no sign of life. Anhydrobiosis is a rare form

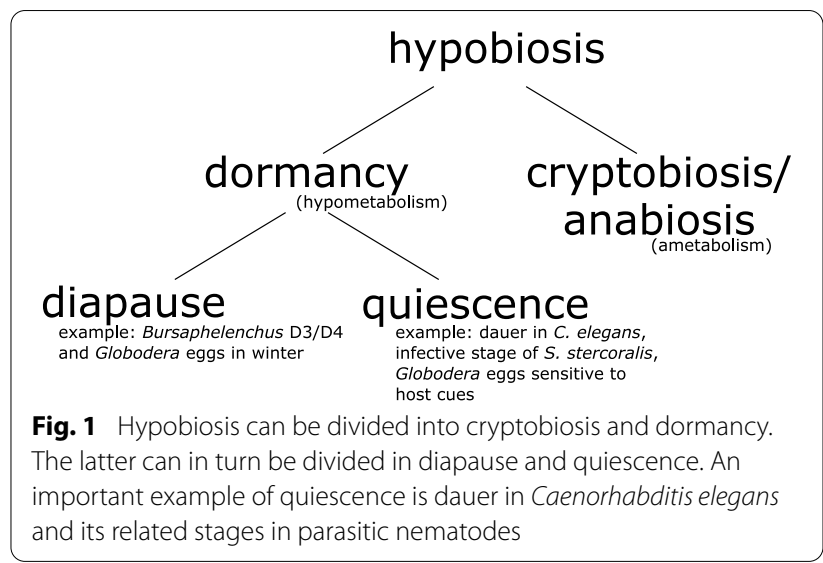

of cryptobiosis, in which a nematode species can survive without water. Dormancy, on the other hand, is a fairly ubiquitous phenomenon among nematodes. Dormancy comprises two related but non-identical states: diapause and quiescence [11].

Organisms in diapause are dormant according to season, under influence of temperature, and remain in this state for a set time, even if favourable circumstances return [12]. An example of diapause in nematodes are the Bursaphelenchus xylophilus dispersal stage 3 and 4 (D3, D4) juveniles that stay dormant in winter [13]. Similar features are seen in cyst nematodes of the genera Globodera and Heterodera; pre-parasitic second stage juveniles (pre-J2) go into a seasonal diapause in winter or summer, while still inside the egg $[14,15]$. While in diapause, they are insensitive to external host cues that otherwise would induce hatching. Diapause might be lifted by a certain temperature sum, for example, or rising spring temperature. Once diapause is lifted by the increasing temperatures of spring, they are perceptive to hatching stimuli again. Until they perceive these host-derived stimuli, they remain quiescent. A quiescent organism responds to abiotic or biotic cues in order to synchronize its development with its environment [11]. The best-studied form of quiescence in nematodes is dauer, first identified in C. elegans [16]. Moreover, quiescence is widely spread across zooparasitic nematodes, such as Strongyloides spp., and is exited upon perception of a host cue. In general, parasitic nematode species may enter diapause or quiescence, and often they can do both.

\section{The dauer stage}

All nematodes go through four larval stages, which are called L1 to L4 (larval stage 1 to 4) for free-living and zooparasitic nematodes, and J1 to J4 (juvenile stage 1 to 4) for entomopathogenic and plant-parasitic nematodes. Dormancy may occur in distinct life stages in a 
species-dependent manner. The most thoroughly studied form of dormancy is dauer (from the German 'enduring') in C. elegans, which is an alternative L3 stage (Fig. 2a), only entered upon harsh conditions such as crowding, lack of food or high temperature. In dauer, C. elegans displays a distinct morphology: it shows radial constriction, has alae (longitudinal ridges in the cuticle), a sealed buccal plug that does not allow feeding, and a double cuticle which ensures resistance to stresses such as desiccation and toxic chemicals $[10,16]$. Moreover, C. elegans dauers rely on storage lipids as a source of energy, as evident from the increased activity of enzymes in the glyoxylate pathway in dauer worms compared to other developmental stages [17-19]. The developmental decision to enter dauer is made 15 to $33 \mathrm{~h}$ after hatching [20] depending on the abovementioned environmental conditions. If these are favourable, the worm develops into L3, L4 and reproductive stages, but if not, it enters the pre-dauer state L2d and subsequently dauer. The dauer stage can last for months, and only when ambient conditions improve will the worms exit dauer and resume reproductive development. Dauer is also a dispersal stage with accompanying behaviour, called nictation, a movement in which the worm stands on its tail and waves its upper body, trying to attach to a vector in order to hitchhike to a new environment [21]. Additionally, the dauer worm is attracted to $\mathrm{CO}_{2}$, which facilitates the detection of potential vectors [22].

Dauer occurs in all members of the genus Caenorhabditis, as well as in other closely related free-living nematodes such as Pristionchus pacificus. Sudhaus [10] defined the dauer larva as an alternative third stage juvenile which does not feed, has a closed stoma and retains the moulted cuticle of the previous stage as a protective sheath'. Many parasitic nematodes have an infective stage that resembles the C. elegans dauer. Riddle [23] wrote in C. elegans II that it seems likely that diverse parasites will have used similar (to the basic signal transduction machinery in C. elegans) internal pathways linked to different cues', in order to incorporate host cues into the regulation of dauer entry and exit. Whereas in some parasitic nematodes dauer is an alternative life stage only entered upon certain (unfavourable) conditions, in others it is an obligate stage that will be entered during every cycle, regardless of ambient conditions (Fig. 2).

Curiously, nematologists from different fields use different definitions. Zooparasitic scientists use a strict definition that approaches that of Sudhaus and does not consider the infective larval stage of a zooparasite to be a dauer stage, although the helminth community acknowledges that the infective larval stage probably arose from the dauer stage [24]. In plant-parasitic nematology, a wider definition of dauer is used which does not distinguish between the equivalent of the $C$. elegans dauer stage and the infective stage of parasitic nematodes (ref. [25] and Figs. 2, 3). The consequence is that dauer is difficult to define exactly and is actually a collection of stages of quiescence, having in common the absence of ageing and feeding and, as we will explain in the next paragraph, the probable conservation of genes of a specific part of the dauer signalling pathway.

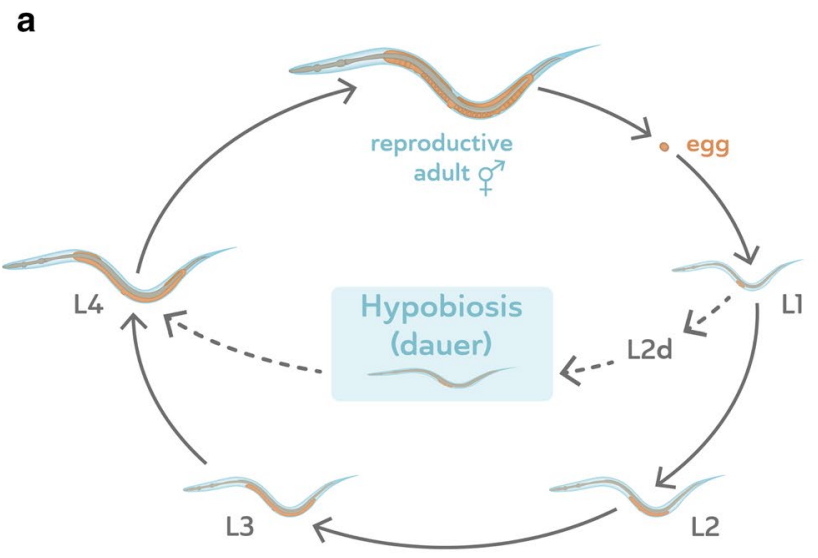

C. elegans

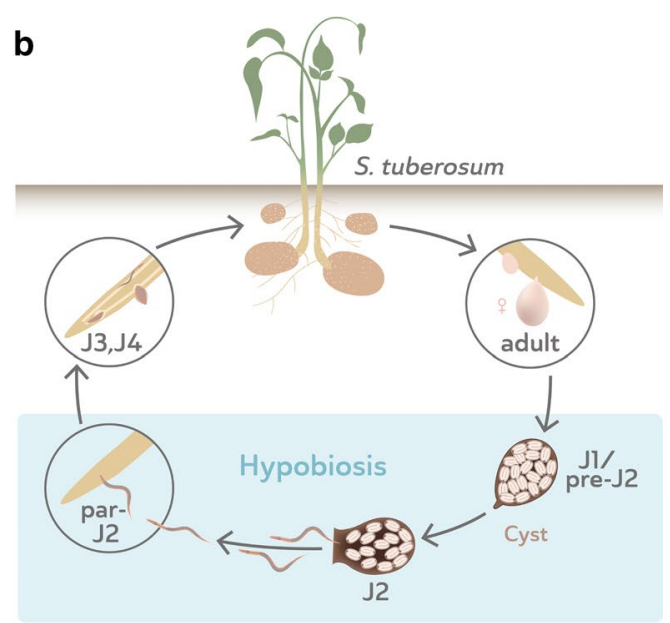

G.pallida

Fig. 2 The life cycles of the free-living model nematode Caenorhabditis elegans (a) and the parasitic potato cyst nematode Globodera pallida (b). The hypobiotic stage in each species is indicated with a blue box. L1, L2, L3, L4 = larval stage 1, 2, 3 and 4. J1, J2, J3, J4 = juvenile stage 1, 2, 3 and 4. Pre-J2 $=$ pre-parasitic juvenile stage 2 . Par-J2 = parasitic juvenile stage 2 


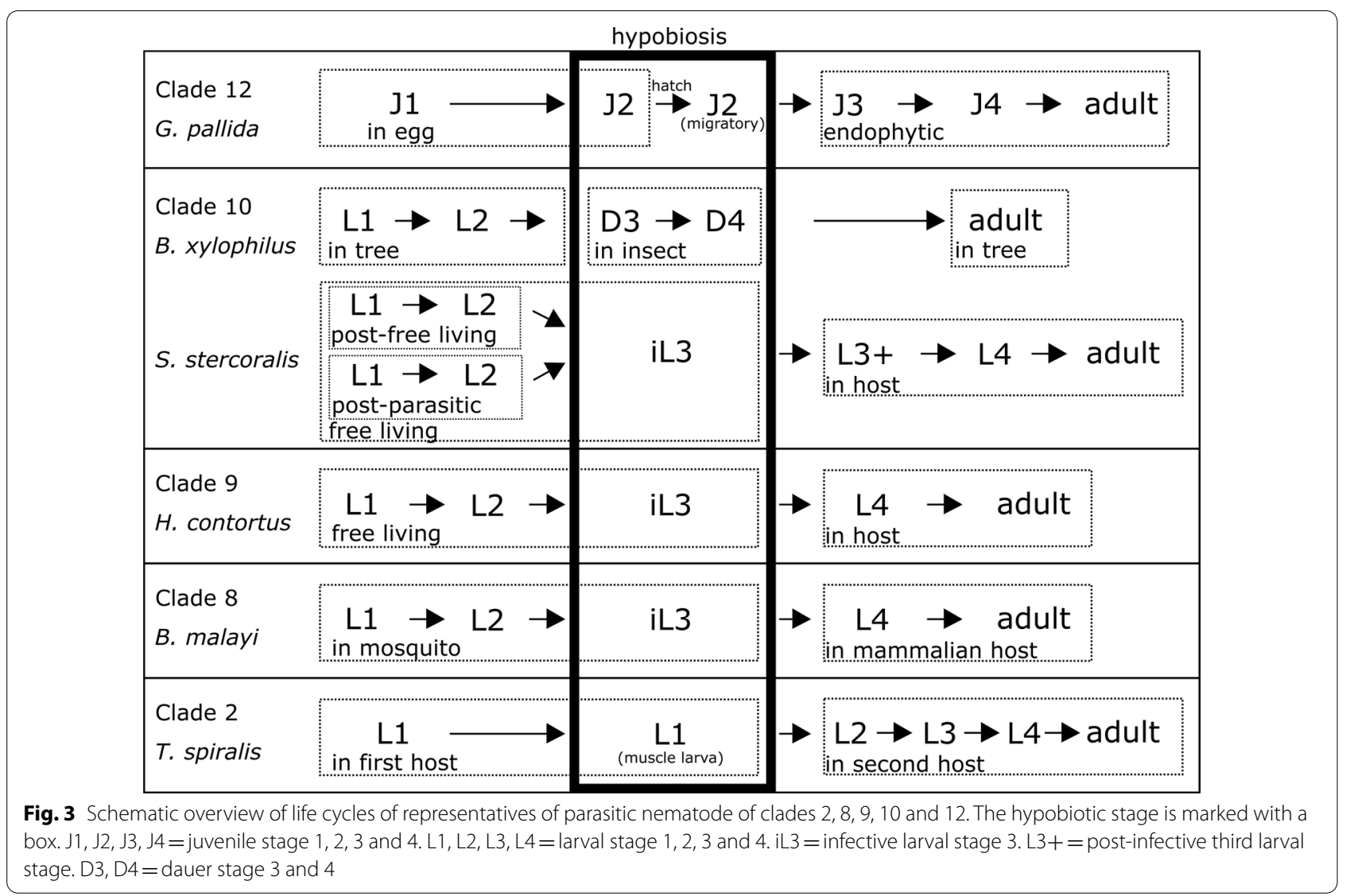

\section{The dauer signalling pathway}

The dauer signalling pathway has been thoroughly studied, mainly because of its role in ageing [26] and the analogy of dauer with the infective stages of zooparasitic nematodes causing disease in humans and animals [24]. Roughly, this pathway consists of four sub-pathways: the cyclic guanosine monophosphate (cGMP) signalling pathway, which feeds into the parallel transforming growth factor beta (TGF- $\beta$ ) and insulin/insulin-like growth factor 1 (IGF-1) pathways, which in turn feed into the dafachronic acid (DA) biosynthesis pathway (Box 1, Fig. 4). The first three are conserved throughout most of the animal kingdom; the latter is specific to the phylum Nematoda.

In the second messenger system, recognition of a ligand by a G-protein-coupled receptor (GPCR) results in the production of a secondary messenger such as cGMP. This is a ubiquitous system for signal transduction found in many different cell types, not only in animals, but also plants and fungi. It allows for extracellular signals to be communicated towards an intracellular response, for example in the case of perception of hormones. The $C$. elegans genome encodes more than 1000 gpcr genes, of which most are nematode-specific [27], and gpcr genes have also been identified in other nematodes [28]. They play roles in chemotaxis and more specifically, for parasitic nematodes, in host detection [29-31]. The TGF- $\beta$ signalling pathway is involved in multiple cellular processes in animals, such as development, differentiation, immune reaction and growth [32]. In C. elegans, this pathway regulates, apart from dauer, body size, axon pathfinding and male copulatory organ development [33]. Also, the insulin/IGF-1 pathway is found throughout the animal kingdom and has been shown to be involved in ageing [34]. Thus, these three sub-pathways are not singularly linked to dauer in nematodes, but the pathway they converge on, the DA signalling pathway, is. DA is synthesized from cholesterol by multiple enzymes, of which some are as yet unknown. The last biosynthetic step is executed by DAF-9, a cytochrome P450 (CYP450) enzyme $[35,36]$. This results in the formation of DA, that binds to the nuclear receptor DAF-12, which prevents dauer entry or results in dauer exit (ref. [37, 38] and Fig. 4). Although DA was detected in all life stages, a 30-fold increase in its concentration is measured upon dauer evasion [39]. Since the DA biosynthesis pathway has been shown to be specifically responsible for the regulation of dauer, we postulate that the conservation of 
this pathway, and hence a peak in (chemical analogue of) DA biosynthesis upon exit of a hypobiotic stage, is a prerequisite to classify a quiescent stage as dauer, in addition to the absence of ageing and feeding that were mentioned earlier.

\section{The pre-adaptation concept}

The phylum Nematoda is divided into 12 clades, and the greatest diversity in parasitic lifestyles is found in Clades 8 to 12 , formerly referred to as the Secernentea (Fig. 5 and ref. [40]). Additionally, parasitic nematodes are present in Clades 1 and 2. Clade 9 harbours many bacterivorous species with a preference for saprobious habitats, which favour the development of parasitism, according to the pre-adaptation concept described by Sudhaus [10]. In short, basal members of Clade 9-mainly Rhabditidaelive in dead and decaying organic matter, which are isolated sources of bacterial food that may be decomposed and are exhausted in a short period of time-the socalled cycles of boom and bust [41]. To adapt successfully to a zooparasitic lifestyle, these nematodes evolved the following characteristics: (i) the capacity to survive under low oxygen levels, (ii) the capacity to withstand varying osmotic pressures, (iii) a tolerance to digestive enzymes produced by bacterial and fungal decomposers, (iv) a tolerance to high temperatures, (v) increased reproductive capacity, and (vi) the capacity to use vectors to disperse among isolated habitats and (vii) to redirect or arrest development to prevent complete exhaustion of reserves until a new food source has been found [10]. The latter two of these pre-adaptations require the nematode to redirect its development into an enduring stage, in order to survive for a long time under unfavourable conditions. Here, too, nematodes in this stage are devoid of an external food source and hence will lower their metabolism. Furthermore, they need to withstand adverse environments while at the same time trying to localize and enter a vector, usually an insect, to be transported to a new food source, where they can resume development. Hostile conditions are common, and it is expected that free-living nematode species, that can enter dauer, spend most of their lifetime in this state [42].

For the evolution of animal (invertebrate and vertebrate) parasitism in Clade 9, the seven pre-adaptations described by Sudhaus [10] are essential. There are several intermediate life forms between free-living and parasitic nematodes, and it is assumed that via these, parasitism in this clade has evolved. From the above-described phoretic relationship, in which nematodes travel to new habitats using insect vectors to which they do not inflict any harm, nematodes developed a lifestyle called necromeny [10]. This is a commensalistic symbiosis in which one organism benefits greatly, whereas the other is unaffected, a lifestyle common in Pristionchus species [37]. In necromeny, nematodes remain in a developmental arrest in the insect without derogating the latter, until the insect dies, after which the nematodes start feeding on the bacterial community that invades the insect corpse [10]. The next evolutionary step towards parasitism is entomoparasitoidy, occurring for example in the Heterorhabditidae, in which the nematode reproduces inside the insect and the insect is killed by nematode-associated microbes. Offspring can then feed on a pre-digested nutrient broth in the insect corpse, which disqualifies this lifestyle as truly parasitic, since the nematode itself does not inflict harm onto the insect, but instead, the associated microbes do [10]. Nevertheless, from here, the step towards true parasitism is small. Outside Clade 9, facultative parasitism occurs, in which the nematode retains the option to complete its life cycle independent of a host, while, if a host is available, the nematode will take advantage and parasitize [38]. By contrast, obligate parasites are fully dependent on the availability of their host; if available, they proceed with reproductive development for multiple generations and thereby quickly colonize their habitat-for example, small ruminants in the case of the parasite Haemonchus contortus [43]. If a host is not available, some of the Clade 9 species can stay dormant for months [16], only to resume reproductive development as soon as a host reappears (Fig. 3).

\section{The dauer hypothesis}

Dauer-like features are observed in both free-living and parasitic nematodes throughout Clades 8 to 12 , even though their life cycles differ substantially (Figs. 2, 3). Parasites need to adjust their life cycle to that of their hosts in order to ensure food availability by efficiently infecting them. Quiescent stages are a means to achieve synchronization, and these are analogous to the dauer in C. elegans [41, 44], which is a facultative third larval (L3) stage. In Clades 8, 10 and 12, quiescent juveniles display more deviations from dauer, although they still have one or more of the following features: radial constriction, a thickened cuticle, sealed buccal capsule and non-feeding behaviour.

The hypothesis that dauer is one of the prerequisites for the evolution of parasitism in Clade 9 is formulated in 'the dauer hypothesis' [10, 24, 41, 44]. However, this hypothesis has largely focused on zooparasites of Clades 8,9 and 10, whereas indications for a dauer state also exist in Clade 12. Moreover, this concept is probably true for the Strongylida of Clade 9, which presumably arose from bacterivorous rhabditids. Yet, there is no phylogenetic evidence that parasitism has evolved in a similar way in Clade 8 , since a bacterivorous ancestor has not been found in this clade. Clade 12 contains several 
species with a clear infective stage, including some typical dauer phenotypes, as well as species without [45]. Because of these inconsistent observations, it is not straightforward to make a claim about dauer in Clade 12. Moreover, the small number of molecular studies regarding dormancy in this clade and their phylogenetic distance to Clade 9 makes direct comparisons complicated.

Nevertheless, we hypothesize that dauer is critical in the evolution of parasitism in Clades $8-12$, because it is required to deal with the unpredictability of the presence of a suitable host combined with the nematode's limited mobility. Here, we will use available knowledge on dauer in C. elegans and parasitic nematodes of Clades 9 and 10 as a starting point to discuss this hypothesis. We do this using the definition of a dauer larva as non-ageing, nonfeeding, and able to synthesize endogenously a (chemical analogue of) DA to exit the dauer state. Additional morphological characteristics, such as radial constriction and/or a sealed buccal capsule, the ability to survive some degree of desiccation, and adopting a coiled posture, can be part of the dauer state, but are not ubiquitous. To conclude, we will review the dauer-like behaviour in plant-parasitic nematodes of Clade 12, and discuss the experimental data that support the occurrence of a dauer stage in this clade.

\section{Box 1 detailed description of the dauer signalling pathway in Caenorhabditis elegans}

Entry into dauer is regulated by the canonical dauer signalling pathway (Fig. 4), which is initiated by the perception of ascarosides, in particular the dauer pheromone, which is a mixture of specific ascarosides $[46,47]$. Ascarosides are species-specific mixtures of 3,6-dideoxy-L-sugar ascarylose derivatives that are excreted and subsequently perceived by nematodes, usually of the same species, in the direct environment. Several different developmental processes are regulated by ascarosides, among which is dauer entry. An increase in the level of dauer pheromone in the environment, consisting of a specific mixture of ascarosides, will result in dauer formation [41, 48-51]. In $C$. elegans, ascarosides are perceived in the sensory neurons of the amphids. Out of 150 discovered ascarosides [52], ascarosides (ascr) \#1, \#2 and \#3 are perceived by GPCRs, SRBC-64 and SRBC-66 [53], whereas ascr\#5 is perceived by GPCRs SRG-36 and SRG-37 [54]. Two more GPCRs, dauer formation-37 (DAF-37) and DAF38 , are involved in perception of ascr\#2 and ascr $\# 2$, 3 and 5, respectively (ref. [55] and Fig. 4). This shows that the perception of different ascarosides is partially overlapping and sometimes redundant between different GPCRs, which suggests the existence of both promiscuous and specific receptors. Indeed, more than 1000 GPCRs are predicted to be present in the genome of C. elegans [56, 57], and they play a critical role in the physiological response to a variable environment. When a GPCR in a neuronal cell is activated, it blocks or stimulates, via its G-protein- $\alpha$ subunits, gpa-2 and gpa-3, and the transmembrane guanylyl cyclase DAF-11, the production of the secondary signal cGMP (Fig. 4). This signal targets the $\alpha$ and $\beta$ subunits of a cyclic nucleotide-gated ion channel, TAX-2 and TAX-4 [58]. Subsequently, the production of insulin-like peptides (INS) and TGF- $\beta$ is stimulated, and these signals are relayed to the insulin/IGF-1 and TGF- $\beta$ pathways, respectively, in parallel [57]. The secretion of DAF-28, an INS, is stimulated through ASNA-1, a conserved ATPase. INSs involved in dauer bind to insulin receptor DAF-2, which apart from the dauer signalling pathway also plays a role in ageing, fat metabolism, stress resistance and development [34]. Forty genes encode INSs, of which 19, including DAF-28, have an agonistic effect on DAF-2, preventing dauer. Another 12 INSs have an antagonistic effect on DAF-2, promoting dauer [59]. Through DAF-2, the phosphoinositide-3-kinase (PI3K) AGEing alteration 1 (AGE-1) is activated, and this phosphorylation of phosphatidylinositol 4,5-biphosphate $\left(\mathrm{PIP}_{2}\right)$ into phosphatidylinositol 3,4,5-triphosphate $\left(\mathrm{PIP}_{3}\right)$ in turn activates downstream kinases PDK-1, AKT-1 and AKT-2 [60-62]. AGE-1 is antagonized by DAF-18/PTEN [34]. AKT-1/2 phosphorylate the FoxO transcription factor DAF-16, thereby sequestering it in the cytoplasm (ref. [63] and Fig. 3). Thus, in daf-2 mutants or INSantagonized DAF-2, DAF-16 is not phosphorylated and remains in the nucleus. There, it binds promoters, influencing transcription, through its DNA-binding domain (DBD) [34]. One of the players downstream of DAF-16 is AAK-2, a $5^{\prime}$ AMP-activated protein kinase (AMPK), which directs metabolism towards the glyoxylate and gluconeogenesis pathways [19]. Dauer induction by food scarcity is mediated by the insulin pathway, since the perception of food changes the subcellular localization of DAF-16, requiring the insulinlike peptide DAF-28 [64]. Moreover, at this point, temperature cues feed into the insulin/IGF-1 pathway via $t t x-3$ [65-67]. Hence, not all environmental cues feed into the pathway at the level of the GPCRs.

Besides INSs, nematodes have two other groups of neuropeptides, called neuropeptide-like peptides (NLP) and FMRFamide-related peptides (FLP). These peptides are derived from precursor peptides, transcribed from neuropeptide-coding genes, and will only acquire their final form after extensive post-translational modifications [68]. Next to INSs, flp transcripts likely play a role, since the majority of these genes are 
upregulated during dauer [69]. Specifically, $f l p-10$ and flp-17 play roles in nictation and attraction by $\mathrm{CO}_{2}$ [69]. It is not known whether or how FLPs feed into the dauer pathway specifically, but they are expected to be perceived by GPCRs [70, 71].

In parallel to the insulin/IGF-1 pathway, the TGF- $\beta$ homologue DAF-7 $[72,73]$ is the cytokine binding to the receptor DAF-1/DAF-4 [74, 75]. Upon ligand binding, the receptor phosphorylates DAF-8 and DAF-14, which inhibits the dauer-inducing transcriptional actions of DAF-3 and DAF-5 in the nucleus (ref. [76] and Fig. 4). Hence, an activated TGF- $\beta$ pathway favours reproductive development.

The insulin/IGF- 1 and TGF- $\beta$ pathways converge on the activation of DA biosynthesis genes, which produce two steroids, $\Delta 4$ - and $\Delta 7$-dafachronic acid (DA) $[35,36,77]$. DA precursor cholesterol intracellular transport is mediated by $n c r-1$ and $n c r-2$ [78], and subsequent enzymatic reactions are carried out by Rieske-like oxygenase DAF-36 [79], 3-hydroxysteroid dehydrogenase DHS-16 [80] and cytochrome P450 DAF-9 [35, 81]. DA binds to the nuclear hormone receptor (NHR) DAF-12, resulting in reproductive development [36, 82] by activating transcription of the let-7 microRNAs. These will, in turn, inhibit $h b l$ 1, which stops L2-stage proliferative programs in seam cells, hence dauer induction (ref. [83] and Fig. 4). In the absence of DA, DAF-12 is bound by its corepressor DIN-1, which results in dauer maintenance [84]. The binding of DA, or not, to NHR DAF-12 is the ultimate switch that decides between dauer entry or progression of the life cycle (i.e., reproductive development).

\section{The dauer stage in parasitic nematodes}

Here we will evaluate the phenotypes and underlying molecular mechanisms of dauer stages in zoo- and plant-parasitic nematodes of Clades 8, 9 and 10 and plant-parasitic nematodes of Clade 12. This was done by systematically reviewing the literature, supplemented with the genome information in Fig. 5. To assemble Fig. 5, we used the WormBase ParaSite BioMart orthologue finder tool on a comprehensive list of dauer-related genes from C. elegans and queried all available genomes of parasitic nematodes in this database (ref. [85] and Additional file 1: Table S1). Although this tool has its limitations-it will split large gene families into multiple groups, which can result in the false absence of homologues, e.g. for daf-9, a cytochrome $\mathrm{P} 450$ enzyme, part of a very large gene family with conserved and divergent branches-it does enable one to draw conclusions on clade level. Additional, and more accurate, genomes of parasitic as well as free-living nematode species will further improve this analysis as they become available.

Species in Clade 2 do not harbour the central player involved in DA signalling, daf-12 (Fig. 5). Although they do show some conserved genes in the TGF- $\beta$ and insulin/IGF1 pathways, these are not specific to nematodes and therefore not indicative of a dauer stage. Therefore, quiescent stages in this clade, for example in the muscle larvae of Trichinella spiralis, even though they bear resemblance to the dauer phenotype, are probably the result of convergent evolution rather than dauer. Therefore, this clade falls outside the scope of this review and will not be discussed further.

With regard to the discussion of dauer in Clades 8, 9, 10 and 12, a word of caution is warranted. For the elucidation of the dauer pathway in C. elegans, thorough experimental evidence is available, including genomic, transcriptomic and proteomic studies, and in vivo, in vitro and in silico experiments. C. elegans mutants are readily available from the Caenorhabditis Genetics Center (University of Minnesota), and there are multiple, easily implementable methods for C. elegans transformation available via open access resources such as WormBook. For parasitic nematodes, propagation and genetic tractability are more complicated because of the necessity of a host, which makes the nematode inaccessible during parts of its life cycle [86, 87]. Still, much of the evidence for dauer in parasitic nematodes only consists of genomic and/or transcriptomic data, without in vivo validation. Therefore, we can only assess our hypothesis with caution until more types of functional data become available.

\section{Dauer in Clade 8 parasitic nematodes}

Clade 8 harbours the speciose animal-parasitic orders Ascaridida, Oxyurida and Spirurida and includes zooparasitic species such as Brugia malayi, Toxocara canis and Ascaris suum, as well as invertebrate-associated nematodes and entomopathogens. Many species in this clade are characterized by a life cycle that contains two hosts: an insect as intermediate host and a mammal as the definitive host (Fig. 3). Large parts of the dauer pathway are represented in the genomes of these zooparasitic nematodes (Fig. 5); 55 and 51 dauer pathway genes (out of 64 in C. elegans) were identified in T. canis and $A$. suum, respectively [88]. However, although the first parasitic daf-7 homologue was detected in B. malayi [89], this species does not have many genes, especially in the TGF- $\beta$ pathway, where the R-SMADs and CoSMADs (daf-3, daf-5, daf-8 and daf-14) have not been detected, just as in Clade 2. Moreover, only a few ins 


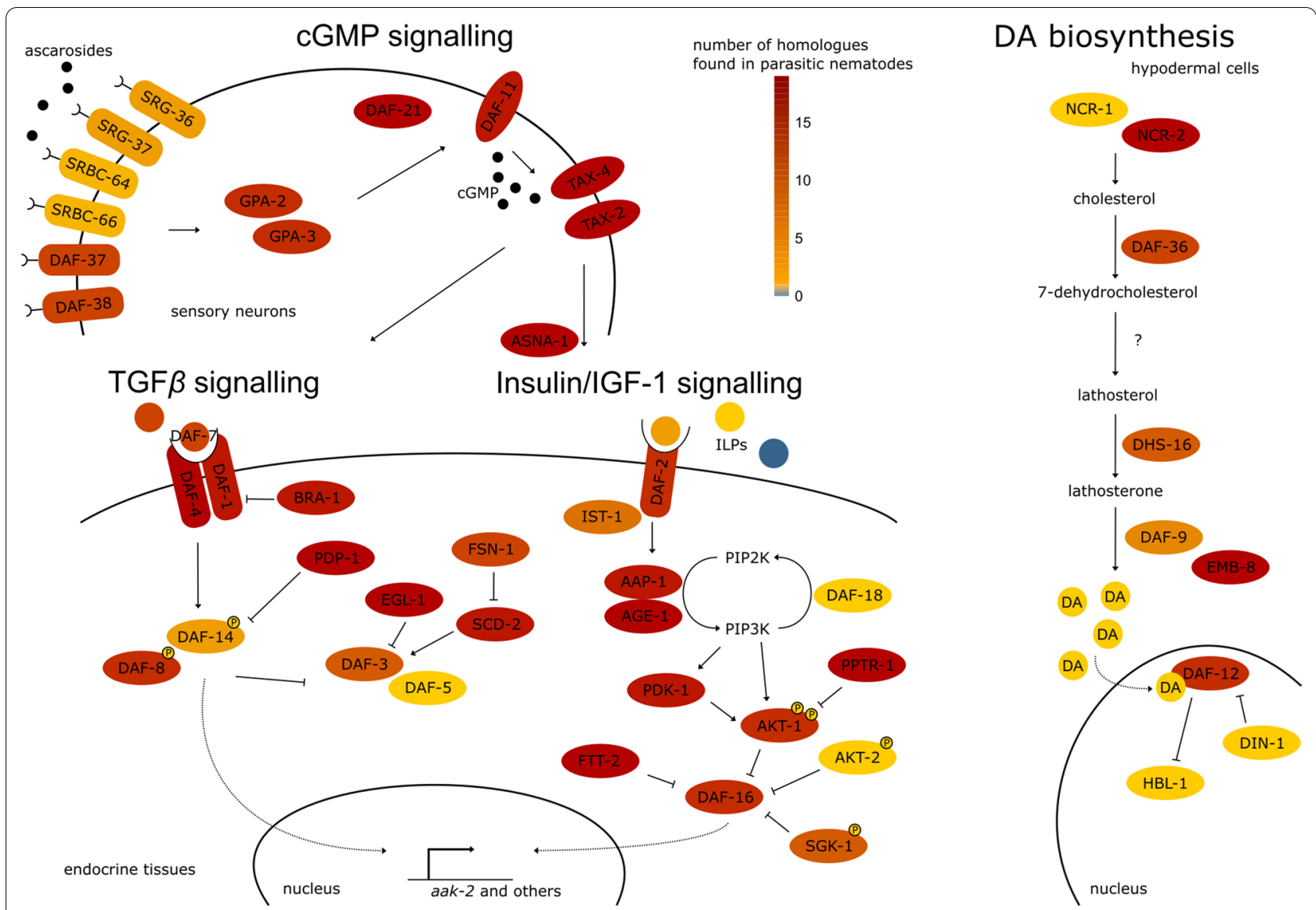

Fig. 4 Schematic overview of the dauer signalling pathway in Caenorhabditis elegans consisting of the cGMP signalling pathway, the parallel TGF- $\beta$ and insulin/IGF-1 pathways, and the concluding DA biosynthetic pathway. The colour scale indicates how conserved each gene is across parasitic nematodes: blue is not conserved, yellow towards red indicates that a gene is less or more conserved. This figure was redrawn from references [1, 166]

genes are present compared to C. elegans (Fig. 5) [88, 90]. By contrast, the DA biosynthetic pathway is largely intact according to the literature [88, 90], Tc-daf-12 and Tcdaf-9 are expressed during the infective stage [91], and the presence of endogenous DA was confirmed in both T. canis and A. suum [88]. Furthermore, a study of Dirofilaria immitis (dog heartworm) DAF-12 shows that it can bind DA with remarkable affinity and moreover that dog cholesterol derivatives can bind, albeit with less affinity, to Dim-DAF-12 and induce moulting from iL3 into L4 stage [92]. In contrast to these findings, the BioMart tool used to assemble Fig. 5 shows an absence of daf- 9 in nearly all Clade 8 parasites, just as was observed for Clade 9 (Fig. 5). From the presence of endogenous DA we infer that this must be caused by the group splitting inaccuracy of the BioMart tool.

In summary, genomic and biochemical analyses suggest that the DA biosynthetic pathway is conserved in Clade 8 parasites and that it regulates dauer, but this is less clear for the upstream parts of the dauer signalling pathway.

\section{Dauer in parasitic Clade 9 nematodes}

Clade 9 comprises some well-studied zooparasites such as Haemonchus contortus, Nippostrongylus brasiliensis and Ancylostoma caninum. These parasites contain a dauer signalling pathway that allows them to parasitize their hosts [24], sheep, rodents and dog, respectively.

In $A$. caninum, host serum stimulates exit from the infective stage and resumption of reproductive development [44]. Using cGMP signalling chemical activators and inhibitors, it was demonstrated that host cue perception is probably mediated by a GPCR [93, 94]. This receptor is not a homologue of Ce-srbc-64, Ce-srbc-66, $\mathrm{Ce}$-srg-36 or Ce-srg-37, since these are dauer pheromone (former two) or crowding (latter two) specific [53, 54] and thus free-living or species-specific, respectively. Indeed, they have not been found in genomes of species outside the genus Caenorhabditis (ref. [90] and Fig. 5).

Not all dauer pathways start with cGMP signalling, as illustrated by $N$. brasiliensis, a nematode whose infective juveniles only resume development upon a temperature 


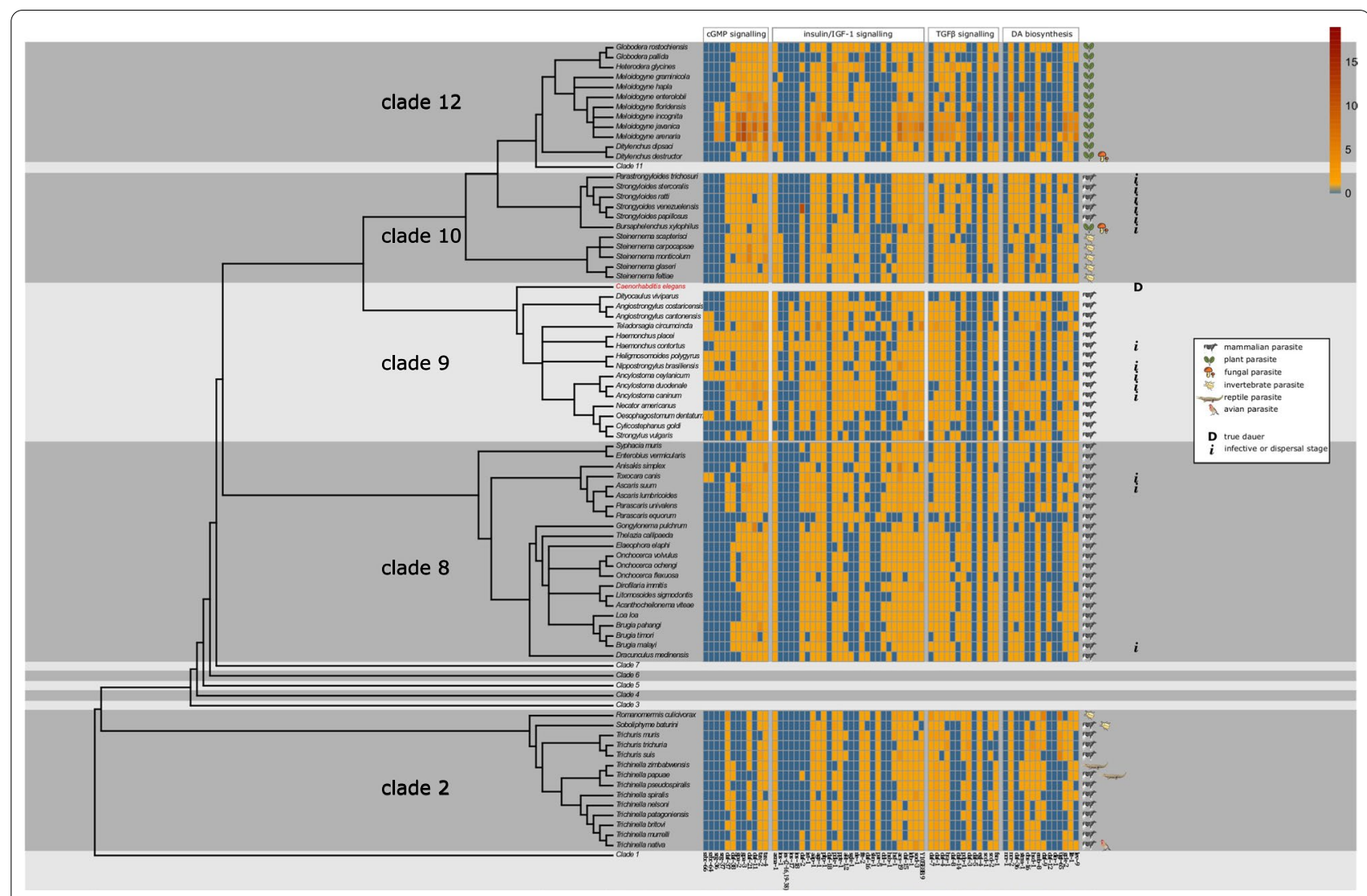

Fig. 5 Phylogenetic tree of Caenorhabditis elegans and parasitic nematodes of which the genome was sequenced and a heat map showing which genes of the dauer signalling pathway are conserved. The type of parasitism each species displays is indicated, as well as whether they have a life cycle with a dauer (only C. elegans) or a confirmed dauer-derived infective stage. The same colour scale as in Fig. 4 was used, blue indicating no homologue, and yellow towards red indicating one or more homologues were detected. In order to assemble this information, we used the WormBase ParaSite (release number 14.0) BioMart orthologue finder tool on a comprehensive list of dauer-related genes and queried all available genomes of parasitic nematodes available in this database (ref. [85], parasite.wormbase.org) using the 'gene stable ID,',gene name,' 'homology type', and the two '\% identity options' within the Orthologues tab in 'Output Attributes'. BioMart orthologue finder tool outputs were generated individually for each C. elegans-to-parasitic species comparison. One-to-one orthologues were taken directly from the output files into the matrix used to prepare the figure. For all other homology types, the most likely orthologues in the parasitic species were chosen by the highest pair of $\%$ identity values. Accession numbers are retrievable in Additional file 1:Table S1

cue. Experiments with chemical inhibitors of specific proteins in the dauer signalling pathway suggest that thermotaxis-induced infective stage exit is not depending on the cGMP signalling pathway, but instead feeds, by unknown means, into the insulin/IGF-1 pathway [95]. Hence, in this nematode, all input for the dauer pathway apart from temperature has been lost. Homologues of the cGMP signalling pathway are still present in the genome (Fig. 5), but might be redundant or have evolved other functions.

Whereas the C. elegans genome encodes 40 ins genes, most zooparasitic genomes in Clade 9 encode fewer (Fig. 5 and ref. [96]). Experiments with chemical inhibitors and in silico studies suggest that the insulin/IGF-1 pathway is conserved to some extent $[95,97]$, but more detailed studies demonstrated a discrepancy between
C. elegans and zooparasitic nematodes. For example, Hc-age-1 could not rescue Ce-age-1 mutants [98], and expression patterns of Hc-age-1 and Hc-pdk-1 only partially overlap with their homologues in C. elegans [99, 100]. The pivotal daf-16 is conserved (Fig. 5) but has fewer splice variants in $H$. contortus and $A$. caninum than Ce-daf-16 [96, 101]. In short, the insulin/IGF-1 pathway is roughly conserved but has many diverged details. In particular, the input (INSs) and output (daf-16 splice variants) seem to have reduced in complexity. This could imply that for these parasites-since dauer is no longer optional such as in free-living nematodes, but rather an obligate stage each juvenile has to pass through-simplification of the pathway has occurred [25], as a decision about entry no longer has to be made. 
Components of the TGF- $\beta$ pathway are less conserved than those of the insulin/IGF-1 pathway [90]. Although most species possess the main players of the TGF- $\beta$ pathway, their expression profile can be different from or even opposite to that in C. elegans. For example, Ce-daf-7 expression is high in L2 and low in dauer worms, whereas in the zooparasitic nematodes of Clade 9, this is inverted [102-105]. Further downstream, expression levels of $\mathrm{Hc}$ daf- 3 and $\mathrm{Hc}$-tgfbr 2 and their respective homologues $\mathrm{Ce}$ daf-3 and $\mathrm{Ce}$-daf-4 show the same opposing trends [106, 107]. Still, Hc-tgfbr-2 is involved in dauer exit, since RNA interference (RNAi) treatment results in a resumption of development (dauer exit) [107]. These differences in expression profiles have been suggested to be a key trait of parasites that have an obligate requirement to enter an arrested stage [103]. Alternatively, the TGF- $\beta$ pathway might have adopted a new role in overcoming immune responses from the host [108].

Further downstream, in the steroid signalling pathway, more conservation is observed, since important players such as daf-12 and daf-9 have homologues in all species of Clade 9 that were sequenced up to now [90], although not all daf-9 homologues were detected in our metadata analysis (Fig. 5). The BioMart algorithm breaks down large gene families into groups of 1500 genes. Since the CYP450 gene family, to which daf-9 belongs, is indeed large, homologues of daf-9 of distantly related species might be undetected erroneously. Indeed, in several of the species where we did not identify a daf-9 orthologue, endogenous DA has been detected (e.g. ref. [105]). Moreover, DAF-12 of A. caninum, A. ceylanicum and N. brasiliensis bind to DA, and this stimulates resumption of feeding $[105,109]$, which further supports a conserved DAF-9-DA-DAF-12 pathway. As a result, DA has been suggested as a potential anthelmintic drug, since it can force iL3 larvae into reproductive development in the absence of a host [110].

As an alternative ligand for DAF-12, bile acids originating from the host have been suggested to bind to zooparasite DAF-12 and hence integrate host cues into the dauer pathway [110]. Although this hypothesis presents an attractive model for the integration of host cues into the dauer pathway, treatment with mammalian-derived cholestenoic acid did not result in resumption of feeding in A. ceylanicum [110], while, by contrast, treatment with DA does, in multiple species $[105,109,111]$. On top of that, daf-9, which encodes the last biosynthetic enzyme for the production of DA in C. elegans, has since been shown to be present in all zooparasitic genomes studied so far (Fig. 5 and ref. [87]). Moreover, chemical inhibition of $\mathrm{Hc}$-DAF-9 prevents recovery from developmental arrest [111], suggesting that zooparasites synthesize an endogenous ligand for DAF-12. Indeed, earlier studies showed that host sterol molecules feed into the dauer pathway upstream of the insulin pathway, rather than into the DA biosynthesis pathway $[65,97,112]$.

In conclusion, these observations show conservation of the DA biosynthetic pathway in zooparasitic nematodes of Clade 9. Furthermore, there are indications that host cues can feed into the dauer pathway upstream of the DA biosynthesis and IGF-1/insulin pathways. Conservation of the other parts of the dauer signalling pathway are less convincing, because of the lack of mutant or biochemical evidence. Moreover, the transcriptional regulation of the TGF- $\beta$ pathway is opposite of that in C. elegans.

\section{Dauer in Clade 10 parasitic nematodes}

In Clade 10, a spectrum of more complex life cycles is observed, ranging from facultative to obligate parasitic, using plants, animals and insects as hosts, and with endo- and ectoparasitic lifestyles. Some well-studied species are Bursaphelenchus xylophilus (pine wood nematode), Strongyloides stercoralis (human pathogen causing strongyloidiasis) and Parastrongyloides trichosuri (mammalian pathogen). The fact that many of the parasitic species of Clade 10 can be reared in the lab, independent of a host, or in the case of B. xylophilus on an alternative host (fungus), has contributed significantly to the thorough studies of the dauer signalling pathway in these species. In general, these parasites show polyphenic development, which means they switch between parasitic and free-living life cycles depending on host availability. For example, S. stercoralis and $P$. trichosuri alternate parasitic generations and free-living generations [28]. L1 larvae, parthenogenetically produced by parasitic females, are excreted in faeces. These juveniles can either immediately become infective larvae, and are developmentally arrested until entering a host, or become a free-living generation feeding on bacteria, in which both males and females exist (Fig. 3). In S. stercoralis, post-free-living larvae (larvae whose parent was free-living) are obliged to enter the infective stage dormancy until entering a host, whereas in $P$. trichosuri multiple consecutive free-living generations may occur $[1,113]$.

The larval stage in which the quiescence occurs is not always L3; Bursaphelenchus xylophilus, for example, has not one but two dispersal stages: one (D3) adapted to navigate towards its insect vector and survive winter, which qualifies it as a diapause rather than quiescence, and one (D4) that perceives a host (pine tree) cue upon which it exits its vector and resumes its reproductive development (Fig. 3). The nematode enters these stages during dispersal by their vector, pine sawyer beetles of the genus Monochamus. In addition to pine wood, they are able to feed on fungi in dead and dying wood. 
The involvement of dauer in the B. xylophilus and $S$. stercoralis life cycles has been studied extensively. Interestingly, the development into or from the infective stage is not only influenced by mammalian host cues. In B. xylophilus, fatty acid ethyl esters (FAEEs) originating from their vector beetles stimulate the nematode to enter the first dispersal stage, D3 [114]. Additionally, monoterpenes, such as $\beta$-myrcene and $\beta$-pinene, from the pine tree cause the nematodes to exit their beetle vector and to resume their development [115]. Moreover, D3 larvae are attracted by $\mathrm{CO}_{2}$, whereas $\mathrm{D} 4$ larvae show avoidance behaviour towards $\mathrm{CO}_{2}$, which reveals another means to enter and exit the $\mathrm{CO}_{2}$-producing insect vector at the right moment [116]. A pheromone that induces infective stage development was identified in both $P$. trichosuri and B. xylophilus [113, 117]. These observations demonstrate that the dauer signalling pathway can integrate multiple biotic and abiotic cues.

In S. stercoralis, 85 chemosensory GPCR genes have been identified, of which the majority are expressed in iL3 or L3 [118], underlining the importance of the integration of environmental conditions into development during and after this stage. At least some of these GPCRs are believed to perceive biochemical host cues, relaying the signal to exit the iL3 stage by the secondary messenger cGMP [118]. Furthermore, in S. stercoralis, the Go subunits binding to GPCRs, are present (Fig. 5 and ref. [119]). In C. elegans, cGMP is perceived by, among others, TAX-4, before downstream signalling activates the TGF- $\beta$ and insulin/IGF-1 pathways. When $\operatorname{tax}-4$ was mutated in S. stercoralis, thermotaxis, necessary for localization and penetration of the host skin, was abrogated [120]. Bursaphelenchus xylophilus is similarly dependent on temperature, since their vectors are inactive in winter. Hence, the nematodes need to arrest their development in winter until spring. Indeed, thermotaxis in this species is also dependent on $B x y$-tax-4 and, in addition, on $B x y$-tax-2 and Bxy-daf-11, as demonstrated by silencing of these genes with RNAi that caused a reduction of the usually long life span under low temperature [13].

In the insulin/IGF-1 pathway, aap-1, age-1, pdk-1 and daf-16 sequences are conserved (Fig. 5) and there is a global overlap in transcriptional patterns [121, 122], although in B. xylophilus, dauer gene transcription is divided over its two dispersal stages (D3 and D4) [114, 122]. Chemical inhibition studies of age-1 in S. stercoralis and B. xylophilus confirmed its conserved role in dauer regulation [114, 121], and Ss-daf-16 rescues Ce-daf-16 mutants [123]. In short, there is a considerable amount of conservation of the insulin/IGF-1 pathway of the Clade 10 parasites.

In the TGF- $\beta$ pathway, existing knowledge of Clade 10 nematodes largely confirms what is seen in Clade 9 parasites. In S. stercoralis, S. ratti and P. trichosuri, daf7 expression is high in the infective stage and low in all other stages [124, 125]. In B. xylophilus, daf-7 expression is upregulated in D3 but not in D4 [114].

A putative homologue of daf-9 was found in S. stercoralis [126] and in B. xylophilus [127]. Expression of the latter is very low in the D3 stage and increases in the D4 stage [127], which is expected since upregulation of daf- 9 signals an exit from the dispersal stage. Furthermore, the cytochrome P450 inhibitor ketoconazole inhibits resumption of feeding in S. stercoralis, implying that endogenous DA is produced by Ss-DAF-9 [126]. SsDAF-12 is one of the most well-characterized proteins of all parasitic nematodes, and its crystal structure has been resolved [109]. It binds DA, and exogenous treatment with DA leads to prevention of or exit from the infective stage [126]. In the closely related species S. papillosus, high DA concentrations prevent the entry into the infective stage [128]. In addition, it was shown that reduced activity of $S$. ratti daf-12 impaired the formation of infective larvae and reduced the severity of infection [129]. Interestingly, according to Stoltzfus et al. [118], in Strongyloides rattii the insulin pathway acts downstream of the steroid biosynthesis pathway, because upon treatment of iL3s with DA, transcription of inss is upregulated. Alternatively, these results could also be explained by a positive feedback loop from the DA biosynthesis pathway to the insulin/IGF-1 pathway. This issue has not been touched upon in other species. In B. xylophilus, daf-12 is upregulated in D3 and D4, showing that it is active when the decision to enter or exit the dispersal stage needs to be made [114, 122, 127]. Furthermore, FAEEs from the vector beetle downregulate DA levels, thereby preventing reproductive development and stimulating entry into the dispersal stages, while exogenous DA treatment blocks entry into the dispersal stages [114].

In conclusion, parasites of Clade 10 have been thoroughly studied with regard to dauer/dispersal stages. Genes involved in thermotaxis are conserved, just as daf-16 in the insulin/IGF-1 pathway and daf-12 in the DA pathway. Intriguingly, independently from the type of host or vector (insect, mammalian or plant), these nematodes can integrate host cues into developmental decisions. The similarities between Clade 9 and Clade 10 with regard to changes in the TGF- $\beta$ signalling pathway suggest that it diverged more from the free-living nematodes than the other parts of the dauer signalling pathway.

\section{Dauer in Clade 12 parasitic nematodes}

Clade 12 harbours both facultative and obligate plant parasites as well as insect parasites. Most attention has been paid to a number of strictly phytoparasitic nematodes such as members of the genera Pratylenchus, 
Ditylenchus, Rotylenchus, Radopholus, Meloidogyne, Globodera and Heterodera. Worldwide agricultural losses due to plant-parasitic nematodes are significant, and seven out of 10 of the economically most destructive plant-parasitic nematodes originate from this clade [130]. In Clade 12, many species are ectoparasites, and hence feed mostly from superficial plant tissues. These species can be compared to, and are sometimes hard to distinguish from, free-living fungivorous species, and they are migratory in all stages [131]. These ectoparasites do not moult into the next stage unless they can feed, and hence they do not survive long without a host.

However, other species of Clade 12 show a clear quiescent stage. For example, the migratory endoparasites of the genera Ditylenchus, Anguina and Pratylenchus are infective during most of their life cycle from the moment of hatching onwards, a common characteristic of migratory endoparasites. When adverse conditions arise, such as absence of a host, low or high temperature, or drought, these species can enter a quiescent state: Radopholus similis can survive up to 6 months in absence of a host [132], Anguina species can survive extreme temperatures [133] and Ditylenchus can enter anhydrobiosis, in which it can survive desiccation for months up to years. A more specific quiescence is present in Ditylenchus dipsaci, where under adverse conditions J4 larvae halt development. The arrested J4s are morphologically different from juveniles under optimal conditions; the former have more lipid reserves, are larger and tend to aggregate [12], which are all also characteristics of the C. elegans dauer larvae [16]. However, few molecular genetic studies have been done on anhydrobiosis or, more specifically, the quiescence in the J4 stage of $D$. dipsaci; thus molecular overlap with the C. elegans dauer pathway is unresolved, and convergent evolution cannot be excluded [40].

In the sedentary endoparasites like root-knot and cyst nematodes, there is a specific infective stage (parasitic J2). For example, the unhatched pre-parasitic J2 (preJ2) can stay inside their egg, dormant in the soil for long periods of time, up to decades for cyst nematodes of the genus Globodera [134], only to hatch when a suitable cue, such as from the host, is perceived. The juveniles hatch as J2, at which point they are morphologically similar to the C. elegans dauer stage, with a thickened (although not double) cuticle and radially constricted shape [135]. Additionally, in the potato cyst nematode (PCN), Globodera rostochiensis, changes occur in the lipophilicity of the cuticle upon hatching under the influence of potato root exudate [136], similar to those in C. elegans larvae exiting dauer [137]. Moreover, they rely heavily on fat deposits as an energy source while they are in the preand par-J2 (pre-parasitic and parasitic juvenile) phases
$[138,139]$, just as C. elegans dauer larvae [140] and soybean cyst nematode, Heterodera glycines, J2 larvae are resistant against toxins [141]. Once hatched, the par-J2 have to locate and enter their host within days in order to establish a feeding site, or they will die (Fig. 2b); they are no longer able to survive an unfavourable environment for an extended period of time.

Therefore, hatching in cyst nematodes needs to be timed in accordance with host presence, i.e. in response to a chemical cue from the host. Subsequently, they need to navigate towards their host, probably using $\mathrm{CO}_{2}$ as cue and chemotaxis, in response to chemicals emitted by their host root, such as volatiles, that act as long-distance cues and/or water-soluble compounds that act as more local cues [142]. The sensitivity towards host chemicals for hatching varies considerably. Meloidogyne eggs hatch spontaneously upon abiotic cues, such as hydration or temperature increase, and do not require host cues, which might be related to their unusual broad host range. By contrast, soybean and beet cyst nematode $(H$. glycines and $H$. schachtii) hatching is stimulated by hostspecific root exudates, but also by abiotic cues such as hydration [143]. On the other side of the spectrum, the PCNs, Globodera pallida and G. rostochiensis, show little spontaneous hatching by hydration and require a specific chemical stimulus present in potato and tomato root exudates [143]. Indeed, these PCNs have a very narrow host range. Heterodera glycines, G. pallida and G. rostochiensis require triterpenoid hatching factors, coined eclepins. Glycinoeclepin A, B and C have been isolated from soybean and kidney bean, both $H$. glycines hosts, and these induce hatching of $H$. glycines [144], whereas solanoeclepin A has been identified in potato root exudate and induces hatching in G. pallida, G. rostochiensis, G. ellingtonae and G. tabacum $[145,146]$.

All molecular studies on possible dauer-like signalling pathways in Clade 12 parasitic nematodes were done on the phylogenetically distally positioned genera Meloidogyne, Globodera and Heterodera, except for one study conducted in Radopholus similis. Transcriptional analysis of juveniles of the latter species displayed upregulation of several genes in the insulin and DA biosynthesis pathways compared to other stages [147], suggesting that the dauer signalling pathway plays a role in the quiescence of this migratory endoparasite.

In Meloidogyne hapla, 14 strong and three weak orthologues of $20 \mathrm{C}$. elegans dauer pathway genes have been reported [148]. Expression studies in Meloidogyne incognita showed that hatched J2 direct their metabolism towards the glyoxylate pathway, which produces carbohydrates from storage lipids. The temperature- or hydration-induced hatching in Meloidogyne spp. shows resemblance to the temperature-induced recovery 
from the infective stage in $N$. brasiliensis of Clade 9. As described above, in this zooparasite, a temperature cue feeds into the dauer signalling pathway after the cGMP pathway, but before the insulin pathway [95]. Although hatching of Meloidogyne spp. is induced primarily by abiotic factors, chemotaxis post-hatching likely involves a cGMP-mediated pathway [149]. Interestingly, several genes of this pathway, such as gpa-2, gpa-3, daf-11, daf21 and $\operatorname{tax}-4$, seem to have undergone multiple duplications, which has not been detected in any other nematode species (Fig. 5). In M. incognita, too, parts of a cGMP signalling pathway have been identified, and functional characterization of Mi-tax-2 and Mi-tax-4-in Clade 10 parasites, such as S. stercoralis and B. xylophilus, involved in perception of temperature signals and thus involved in the relay of the dauer cue-by RNAi showed behavioural defects. These were observed particularly in host detection, and knockdown resulted in perturbed chemotaxis towards chemicals such as ascarosides [149].

Chemotaxis also occurs in the cyst nematodes [150]. FMRF-amide-like peptides (FLPs) are responsible for locomotion [151], so they could be responsible for initiation of movement after hatching in G. pallida, marking the activation of the dauer exit pathway in order to exploit a suitable food source, and ultimately, redirect development towards reproduction. Indeed, the expression of flps is upregulated in the H. avenae [135] and G. pallida [69] par-J2 stage, just as in C. elegans dauer [69]. The involvement of $f l p s$ in locomotion associated with dauer is further supported by the fact that downregulation of $f l p s$ in the closely related root-knot nematode species $M$. incognita and M. graminicola reduces hatching and infectivity [152-155].

Information on conservation of the downstream parts of the dauer pathway in cyst and root-knot nematodes is scarce. However, the insulin pathway seems to be conserved in Meloidogyne spp., since many homologues, including the pivotal $d a f-2$ and daf-16, were detected in the M. incognita and M. hapla genomes. Downregulation by RNAi of Mi-daf-16 and Mi-skn-1, encoding a transcription factor acting parallel to DAF-16, reduced the hatching rate, infectivity, growth and reproduction rate [156]. Additionally, players in the DA signalling pathway such as daf-9 and daf-12 were identified [90, 157]. For the majority of species, the pivotal $d a f-12$ gene was detected in the genome (Fig. 5). Mi-nhr-48, of which the homologue in C. elegans is the closest paralogue to daf12 , is essential for pathogenicity, but a connection to the dauer pathway was not made [140]. In conclusion, apart from bioinformatics studies, there is little functional evidence for a dauer pathway in the Clade 12 plant-parasitic species.
Indeed, several comparative genomics $[158,159]$ and transcriptomics $[135,159]$ studies conclude that there is no overlap between dauer signalling and hatching followed by host-finding behaviour of cyst and root-knot nematodes. For example, transcriptional patterns in hatched $\mathrm{J} 2$ of $\mathrm{H}$. glycines did not match those of C. elegans dauers [159], and only a few homologues of dauer pathway genes were found in the G. pallida genome, and treatment with cGMP unexpectedly inhibited hatching in quiescent nematodes under the influence of potato root diffusate (PRD) [158]. However, below we provide arguments why these results do not necessarily refute the hypothesis that dauer is involved in the infectious stages of these plant-parasitic nematodes. Firstly, the timing of sampling is crucial, since it is not clear what marks the end point of quiescence in cyst nematodes: the hatch of $\mathrm{J} 2$ (i.e., resumption of nematode movement), or the resumption of feeding and the subsequent moult from $\mathrm{J} 2$ to J3 inside the host. On the one hand, hatching marks an increase in mobility and an end to the stress-resistant and non-feeding long-lasting survival stage. On the other hand, infective stages of parasites usually end when the parasite has entered its host and moults into the next larval stage, and moreover, motile $\mathrm{J} 2$ in search of the host plant are the functional equivalent of the iL3 stage of zooparasitic species. It is not clear, and difficult to ascertain, which of these options is most likely, and the transcript level of dauer signalling pathway genes should be evaluated in order to provide clarity. Secondly, sampling of large numbers of $\mathrm{J} 3$ nematodes is not trivial, since by then the larvae are inside the host. The same problem holds for sampling of J1 juveniles, because they are mostly present in immature cysts, attached to the plant root. Hence, making a detailed comparison between J1, before developmental arrest, J2, still in arrest, and J3, which just resumed development, is difficult. The abovementioned studies do not compare these critical stages, and relevant dauer up- or downregulated genes are therefore likely to remain concealed. Thirdly, the currently available genome sequences of many Clade 12 nematodes are highly fragmented, which will result in incomplete read mapping and thus an incomplete analysis of differentially expressed genes. Finally, because of the large differences in the environments to which C. elegans dauers on the one hand, and cyst and root-knot nematodes on the other are exposed, it is highly unlikely that lifestage-specific transcription is similar. For example, a G. rostochiensis hatched $\mathrm{J} 2$ juvenile resides in the soil and needs to find its host as soon as possible, upon which it needs to be able to penetrate the root. This will require transcription of specific receptors involved in chemotaxis for navigation and plant cell wall-degrading enzymes for 
root entry. By contrast, the C. elegans dauer, which can be found in a range of environments, might nictate but otherwise is mostly immotile and not actively pursuing host cues. Moreover, phytoparasitic nematodes acquired a number of effectors, in part via horizontal gene transfer, which are active in the infective stage [160], and homologues of these genes will not be found in C. elegans. Hence, cyst and root-knot nematode infective stages likely display a very different transcriptional pattern from that of C. elegans dauer larvae, and other experimental approaches are necessary to prove or refute the hypothesis that dauer signalling is responsible for quiescence in Clade 12 parasites.

\section{Implications and prospects on dauer in parasitic nematodes}

Throughout the phylum Nematoda, numerous parasitic lineages arose independently, and different types of quiescence have evolved since parasites need this feature to synchronize their life cycle with their host [41]. Although in thoroughly studied animal-parasitic nematodes of Clades 9 and 10 the infective juvenile usually is in the third larval stage (iL3), this cannot be generalized to nematodes with other parasitic lifestyles. Within the phylum Nematoda, there are examples of dormancy in any larval stage. For example, Clade 8 Brugia malayi arrests in L1 (Fig. 3) and Clade $12 \mathrm{H}$. schachtii arrests in J2. Whereas dormancy occurs throughout the phylum, the dauer stage is specific for Clades 8 to 12 . However, in many species, next to an infective stage or dispersal stage, a diapause is observed, which is entered depending on the season, such as in H. contortus, [161], B. xylophilus [13] and G. rostochiensis [162]. When in diapause, nematodes do not respond to host cues. Hence, dauer is only a specific type of hypobiosis, whereas multiple other types of hypobiosis occur throughout the phylum in both parasites and free-living nematodes. However, of these hypobiotic stages, dauer is the most completely molecularly elucidated survival stage, because it is the most prominent form of hypobiosis in the model organism $C$. elegans.

In parasitic nematodes closely related to C. elegans, there is overlap in morphological and behavioural aspects of dauer, such as the buccal plug, radial constriction, double cuticle and the ability to survive desiccation. In the dauer-like stages of parasites from different clades $(8,10,12)$, these morphological characteristics are less pronounced or absent. This suggests that these aspects of dauer were not selected for in the evolution of parasitism; only the ability to bridge time in food scarcity was [41]. Nevertheless, although the morphological features of the dauer juveniles diverged in these distant clades, the molecular mechanisms underlying this survival trait are likely conserved, as we discuss in the present review.

The GPCRs that perceive dauer pheromone, a mixture of ascarosides, in C. elegans are not at all conserved, not even in other Caenorhabditis species. This is not surprising, since ascarosides are highly species- and habitat-specific. Additionally, GPCRs are presumed to be involved in chemotaxis and perceiving host cues, but similarity in chemotaxis between species is not explained by phylogeny, but rather by host preference [108]. Indeed, this system is evolutionary easily adaptable and thus can diverge quickly, as illustrated by several accelerated evolution experiments. For example, when worms were grown in high density for multiple generations, their offspring acquired multigenic resistance to crowding-induced dauer because of a disruption in receptor genes srg-36 and srg-37 [54]. In another experiment with the polyphenic nematode P. trichosuri (Clade 10), it was demonstrated that natural variation in sensitivity to dauer-pheromone-like cues, produced by free-living worms of the same species, exists in the population [113]. Culturing worms in the presence of these pheromones favoured natural selection for free-living generations, and vice versa. The resulting inbred lines were insensitive or supersensitive, respectively, to the pheromone. Hence, these experiments show how adaptations to the dauer pathway could have arisen. Furthermore, it is plausible that the cGMP signalling pathway and its plasticity play an important role in chemotaxis.

In the insulin pathway, a striking expansion of the ins gene family has occurred in C. elegans, most of which are absent in parasitic nematodes (Fig. 5), and also in other Caenorhabditis species [90]. Generally, only the antagonists of insulin receptor DAF-2 encoding genes, ins- 1 and ins-18, are widely conserved (Fig. 5 and ref. [90]). It has been suggested that, since no known agonists of DAF-2 are detected in parasitic nematodes, host insulins might serve as a complementary source of agonists for the insulin receptor [163].

The TGF- $\beta$ pathway seems to be the least conserved part of the dauer signalling pathway. Indeed, our genomics meta-analysis shows that a number of important transcription factors-daf-3, daf-5 and daf-14-are not conserved. To a lesser extent, that also holds for daf7 that is not present in Clade 12 and a part of Clade 10 (Fig. 5). Moreover, the expression pattern of the pivotal daf-7 gene in parasites is generally opposite of that in C. elegans [102-105, 114, 124, 125]. There have been multiple suggestions to explain this discrepancy; the TGF- $\beta$ pathway might be adapted to cope with immune responses from the host [108] or has flipped expression patterns since the infective stage is obligatory instead of 
facultative in many parasites [103]. Gilabert et al. [90] suggested that the high expression of daf-7 in C. elegans dauer is derived, and that in ancestors and in contemporary parasites, DAF-7 is mainly responsible for iL3 to adult transition, hence the high expression in infective juveniles.

The almost ubiquitous presence of some genes, such as tax-2, tax-4, daf-1, age-1, pdk-1 and daf-16 (Fig. 5), across all clades is not a suggestion that dauer is ubiquitous as well. Rather, these genes are part of the ancient cGMP, TGF- $\beta$ and insulin/IGF-1 signalling pathways that occur throughout the animal kingdom and hence are not specific for dauer. However, when the group formerly known as Secernentea evolved from Clade 7, it developed a specialized form of quiescence, which is known as dauer, using these ancient pathways to regulate entry and exit. The presence of dauer in the ancestor of Clades 8 to 12 may have enabled the evolution of a dispersal stage, possibly in association with an insect vector. Then, for the evolution into an infective stage in parasites, the pathway may have lost complexity, especially for specialist parasites, as is observed from genomic data in multiple parasitic species in all of the Secernentea clades. Free-living nematodes need to integrate many different cues in order to decide whether or not to enter dauer, depending on what habitat and abiotic conditions they are exposed to. Parasites, on the other hand, have a less variable habitat, since a (large) part of their life cycle occurs in or around their intermediate or definitive host. The presence of these hosts largely determines whether conditions are favourable. For some parasitic nematodes, the infective stage will be entered unconditionally, and the only decision that needs to be made is when the quiescent state is exited. This decision can be made with a cue of low complexity: a molecule originating from the host, or even only a change in abiotic conditions such as temperature or humidity. Therefore, a reduction in dauer pathway complexity is possible. This reduction is visible mostly in GPCRs, complexity of ins signalling and the lack of conservation of the TGF- $\beta$ pathway (Fig. 5). These genes, although still crucial, have reduced in number possibly because a high degree of plasticity is not necessary for parasites because their habitat is less variable than that of free-living nematodes.

It is widely accepted-and substantiated in this review-that many nematodes of Clades 9 and 10 possess a dauer stage-also called infective stage. Despite their phylogenetic distance, we postulate that this analogy can be extended to other parasitic nematodes, such as in Clade 12, even though the occurrence of dauer per se in this group has not been unambiguously demonstrated. A likely explanation for this is the large phylogenetic distance to the model organism C. elegans, which hampers identification of similarities between the C. elegans dauer pathway and infective stage pathways of these plantparasitic nematodes. However, in many of the Clade 12 economically relevant parasites such as the root-knot and cyst nematodes, hatching and subsequent host-finding by chemotaxis are the most pivotal events in infection [142]. These processes rely on host chemicals, which likely feed into the dauer signalling pathway, and the morphology and behaviour of infective $\mathrm{J} 2$ larvae loosely resemble dauer worms of parasites of Clade 9 and 10. Moreover, many homologues of dauer pathway genes are present in the genomes of these species (Fig. 5), despite the as yet suboptimal quality of these genome sequences. However, apart from bioinformatics studies, the experimental evidence is scarce. Thus, although it seems likely that quiescence in Clade 12 is originating from the dauer signalling pathway based on genomics data, functional studies are required to substantiate this hypothesis.

Interestingly, it was suggested that host cues might directly bind to DAF-12 of parasites of Clades 9 and 10 in order to release dauer: mammalian bile acid hormones would bind the A. ceylanicum and D. immitis DAF-12 $[92,110]$. This is a relevant possibility for Clade 12 parasites too, and indeed it was speculated that eclepins may directly activate Globodera and Heterodera homologues of DAF-12 [164], which would support involvement of the dauer pathway in quiescence in cyst nematodes. This would also explain the absence of daf-9 homologues in numerous species (Fig. 5), although we deem it more likely that the BioMART algorithm does not work optimally for the large gene family of the CYP450s, and that hence the absence of $d a f-9$ is erroneous. Indeed, although in zooparasites some host-derived bile acid derivatives can bind to parasitic DAF-12 in vitro, their binding is weaker than that of DA itself, and in vivo experiments show that only the latter is able to promote exit from the infective stage $[92,110]$.

An alternative hypothesis is that host cues feed more upstream into the dauer signalling pathway, more specifically, via GPCRs through the cGMP signalling pathway, similar to dauer pheromones of $C$. elegans. Nematodes contain a wide variety of gpcr genes, which have evolved to perceive species-specific relevant cues. Some of these might perceive cues that initiate dauer exit in order to release the developmental arrest. Indeed, even in nematodes outside Clade 9, such as S. stercoralis of Clade 10, DA and the biosynthetic genes, such as daf-9, are still present [126]. Similarly, daf-9 homologues are detected in Clade 12 parasites, albeit not in all species (Fig. 5). Therefore, it is likely that DA is endogenously produced and not (or not completely) substituted for by hostproduced molecules. Secondly, a host signal feeding into the pathway via a GPCR opens the possibility for 
modification of the signal more downstream, allowing the dauer pathway to integrate several different cues of different origins, thereby retaining the flexibility of the pathway as seen in C. elegans. For example, for B. xylophilus and Heterodera and Globodera spp., these other cues could be temperature, since they can enter a seasonal diapause, which makes them insensitive to host cues $[13,158]$. In conclusion, if the pre-parasitic and/or parasitic J2 stage of cyst nematodes is a state analogous to dauer, then the eclepins are the signal to exit from this dauer-like stage, but it is as yet unknown how these cues are integrated into the dauer pathway of these species. A better understanding of the mechanism behind the integration of these host-derived cues into the dauer signalling pathway could facilitate the development of synthetic analogues that can induce 'suicide hatching' and thereby serve as a specific and effective new control method [165]. Analogous to the plant parasites, similar host cue analogues for zooparasites could reduce their infectivity in humans and cattle. However, both of the above-described hypotheses-direct binding of host cues to DAF-12 and entry of the host cue more upstream into the dauer pathway-are not sufficiently supported by evidence and need to be experimentally confirmed. Although there is a lack of simple transformation tools for plant-parasitic nematodes, many other tools to study the dauer signalling pathway have already proven useful in zooparasites, such as C. elegans complementation studies (e.g. [98]), functional assays with heterologously produced homologues of dauer pathway proteins (e.g. [105]) and in vitro receptor-ligand interaction assays (e.g. [83]).

\section{Conclusions}

Whereas zooparasitic nematologists have coined the term 'dauer' to explain a very specific type of quiescence in free-living nematodes such as C. elegans, and use the term 'infective stage' for derived stages in parasites, the plant-parasitic nematology community mostly uses 'dauer' as a phenotypic trait related to survival under environmental stress and/or food shortage without a confirmed link to an underlying molecular mechanism. We propose here to use dauer only for the non-ageing, non-feeding state, whose entrance and/or exit is regulated by the DA pathway-specifically, by the endogenous production of DA. Phenotypic features and -omics data suggest that the dauer hypothesis can be expanded to include the plant-parasitic nematodes of Clade 12. However, Clade 12 parasitic nematodes display much more variation in dauer-like quiescence than those from Clades 9 and 10. This is perhaps not unexpected, since members of this clade are only distantly related to the best described dauer model, $C$. elegans. The phenotypic and molecular diversification complicates a straightforward identification of similarities between the clades. After Clades 8 to 12 arose from Clade 7 and the first dauer-like stage evolved, the ancient cGMP, TGF- $\beta$ and insulin/IGF-1 pathways were co-opted to regulate this new dauer signalling pathway. The DA biosynthetic pathway, on which these three ancient pathways converge, is specific for Clades 8 to 12 , and thus has evolved after this divergence. In all clades harbouring nematodes with a parasitic lifestyle, host-derived chemical cues influence the quiescence of parasitic nematode species. There is a large body of evidence showing that these cues feed into the dauer signalling pathway, either into the DA pathway or through the GPCRs. We postulate that this is also the case for host cues of the Clade 12 plant-parasitic nematodes.

\section{Abbreviations}

age: AGEing alteration; ascr: Ascaroside; cGMP: Cyclic guanosine monophosphate; CYP450: Cytochrome P450; D3, D4: Dispersal stage 3 and 4; DA: Dafachronic acid; daf: Dauer formation; FLP: FMRFamide-related peptides; gpa: G-protein-a subunit; GPCR: G-protein-coupled receptor; IGF-1: Insulin growth factor 1; iL3: Infective larval stage 3; ins: Insulin-like peptide; J1, J2, J3, J4: Juvenile stages 1, 2, 3 and 4; L1, L2, L3, L4: Larval stages 1, 2, 3 and 4; L2d: Pre-dauer larval stage 2; NHR: Nuclear hormone receptor; NLP: Neuropeptide-like peptide; par-J2: Parasitic J2; PCN: Potato cyst nematode; PI3K: Phosphoinositide3-kinase; PIP $_{2}$ : Phosphatidylinositol 4,5-biphosphate; PIP : Phosphatidylinositol 3,4,5-triphosphate; pre-J2: Pre-parasitic J2; TGF- $\beta$ : Transforming growth factor beta.

\section{Supplementary Information}

The online version contains supplementary material available at https://doi. org/10.1186/s13071-021-04953-6.

Additional file 1: Table S1. The accession numbers of homologues in parasitic nematodes of C. elegans dauer signalling pathway genes, as detected using the WormBase ParaSite (release number 14.0) BioMart orthologue finder tool (ref. [85], https://parasite.wormbase.org) and that was the basis for the construction of the heat map in Fig. 5. If multiple homologues were detected, they are ordered from high to low \% identity.

\section{Acknowledgements}

We thank Dr. Martijn Holterman for providing the phylogenetic tree displayed in Fig. 5.

\section{Authors' contributions}

$\mathrm{LV}$ and $\mathrm{HB}$ designed the manuscript. LV wrote the manuscript. $A B$ assembled and analysed the data for Fig. 5. AB, LD, MR, JK, HH, AG, and HB critically revised the manuscript. All authors read and approved the final manuscript.

\section{Funding}

We acknowledge funding by the European Research Council (ERC Advanced grant CHEMCOMRHIZO, 670211 to HB, LV, LD, MR), the Netherlands Organisation for Scientific Research (NWO-TTW Grant 16873 to HB, AG, AB) and the EU (Marie Curie Grant NemHatch, 793795 to LD).

Availability of data and materials

The datasets analysed during the current study are available in the BioMart WormBase ParaSite repository, https://parasite.wormbase.org/info/Tools/ biomart.html. 


\section{Declarations}

Ethics approval and consent to participate

Not applicable.

\section{Consent for publication}

Not applicable.

\section{Competing interests}

The authors declare that they have no competing interests.

\section{Author details}

${ }^{1}$ Plant Hormone Biology Group, Green Life Sciences Cluster, Swammerdam Institute for Life Sciences, University of Amsterdam, Science Park 904, 1098 XH Amsterdam, The Netherlands. ' 2 Laboratory of Nematology, Department of Plant Sciences, Wageningen University, 6708 PB Wageningen, The Netherlands.

Received: 19 April 2021 Accepted: 13 August 2021

Published online: 27 October 2021

\section{References}

1. Stoltzfus JD, Minot S, Berriman M, Nolan TJ, Lok JB. RNAseq analysis of the parasitic nematode Strongyloides stercoralis reveals divergent regulation of canonical dauer pathways. PLoS Negl Trop Dis. 2012;6:e1854.

2. Blaxter M, Koutsovoulos $\mathrm{G}$. The evolution of parasitism in Nematoda. Parasitology. 2015;142(Suppl 1):S26-39.

3. Holterman M, Karegar A, Mooijman P, Van Megen H, Van Den Elsen S, Vervoort MTW, et al. Disparate gain and loss of parasitic abilities among nematode lineages. PLoS ONE. 2017;12:e0185445.

4. Roeber F, Jex AR, Gasser RB. Impact of gastrointestinal parasitic nematodes of sheep, and the role of advanced molecular tools for exploring epidemiology and drug resistance - an Australian perspective. Parasites Vectors. 2013;6:153.

5. Payne L, Fitchett JR. Bringing neglected tropical diseases into the spotlight. Trends Parasitol. 2010;26:421-3.

6. Zajíčková M, Nguyen LT, Skálová L, Raisová Stuchlíková L, Matoušková P. Anthelmintics in the future: current trends in the discovery and development of new drugs against gastrointestinal nematodes. Drug Discov Today. 2020;25:430-7

7. Nicol JM, Turner SJ, Coyne DL, den Nijs L, Hockland S, Tahna MZ. Current nematode threats to world agriculture. In: Jones JT, Gheysen G, Fenoll $C$, editors. Genomics and molecular genetics of plant-nematode interactions. Dordrecht: Springer; 2011. p. 21-44.

8. Holterman M, Van Der Wurff A, Van Den Elsen S, Van Megen H, Bongers T, Holovachov O, et al. Phylum-wide analysis of SSU rDNA reveals deep phylogenetic relationships among nematodes and accelerated evolution toward crown clades. Mol Biol Evol. 2006;23(9):1792-800.

9. Blaxter ML, De Ley P, Garey JR, Liu LX, Scheldeman P, Vierstraete A, et al. A molecular evolutionary framework for the phylum Nematoda. Nature. 1998;392:71-5.

10. Sudhaus W. Preadaptive plateau in Rhabditida (Nematoda) allowed the repeated evolution of zooparasites, with an outlook on evolution of life cycles within Spiroascarida. Palaeodiversity. 2010;3:117-30.

11. Withers P, Cooper CE. Dormancy. In: Fath B, editor. Encyclopedia of ecology. 2nd ed. Amsterdam: Elsevier; 2018. p. 309-10.

12. Perry RN, Moens M. Survival of the parasitic nematode outside the host In: Perry RN, Wharton DA, editors. Molecular and physiological basis of nematode survival. 1st ed. Cambridge: CABI Publishing; 2011. p. 1-27.

13. Wang B, Ma L, Wang F, Wang B, Hao X, Xu J, et al. Low temperature extends the lifespan of Bursaphelenchus xylophilus through the CGMP pathway. Int J Mol Sci. 2017;18:2320.

14. Banyer RJ, Fisher JM. Seasonal variation in hatching of eggs of Heterodera avenae. Nematologica. 1971;17:225-36.

15. Perry RN. Dormancy and hatching of nematode eggs. Parasitol Today 1989:5:377-83.
16. Cassada RC, Russell RL. The dauerlarva, a post-embryonic developmental variant of the nematode Caenorhabditis elegans. Dev Biol. 1975:46:326-42

17. O'Riordan VB, Burnell AM. Intermediary metabolism in the dauer larva of the nematode Caenorhabditis elegans-II. The glyoxylate cycle and fatty-acid oxidation. Comp Biochem Physiol. 1990;95:125-30.

18. Wadsworth WG, Riddle DL. Developmental regulation of energy metabolism in Caenorhabditis elegans. Dev Biol. 1989;173:167-73.

19. Penkov S, Erkut C, Oertel J, Galli R, Vorkel D, Verbavatz M, et al. A metabolic switch regulates the transition between growth and diapause in C. elegans. BMC Biol. 2020;18:1-20.

20. Schaedel ON, Gerisch B, Antebi A, Sternberg PW. Hormonal signal amplification mediates environmental conditions during development and controls an irreversible commitment to adulthood. PLoS Biol. 2012;10:1-18

21. Lee H, Choi MK, Lee D, Kim HS, Hwang H, Kim H, et al. Nictation, a dispersal behavior of the nematode Caenorhabditis elegans, is regulated by IL2 neurons. Nat Neurosci. 2012;15:107-12.

22. Hallem EA, Dillman AR, Hong AV, Zhang Y, Yano JM, Demarco SF, et al. A sensory code for host seeking in parasitic nematodes. Curr Biol. 2011;21:377-83

23. Riddle D. Genetic and environmental regulation of dauer larva development. In: Riddle D, Blumenthal T, Meyer BJ, Priess JR, editors. C. elegans II. 2nd ed. Cold Spring Harbor Mongraph Series. New York: Cold Spring Harbor Laboratory Press; 1997.

24. Crook M. The dauer hypothesis and the evolution of parasitism: 20 years on and still going strong. Int J Parasitol. 2014:44:1-8.

25. Bird AF, Bird J. Growth and molting. In: Bird AF, Bird J, editors. The structure of nematodes. 2nd ed. San Diego: Academic Press; 1991. p. 75-95.

26. Ewald CY, Castillo-Quan JI, Blackwell TK. Untangling longevity, dauer, and healthspan in Caenorhabditis elegans insulin/IGF-1-signalling. Gerontology. 2019;64:96-104.

27. Bargmann $\mathrm{Cl}$. Neurobiology of the Caenorhabditis elegans genome. Science. 1998:282:2028-33.

28. Hunt VL, Tsai IJ, Coghlan A, Reid AJ, Holroyd N, Foth BJ, et al. The genomic basis of parasitism in the Strongyloides clade of nematodes. Nat Genet. 2016;48:299-307.

29. Bernot JP, Rudy G, Erickson PT, Ratnappan R, Haile M, Rosa BA, et al. Transcriptomic analysis of hookworm Ancylostoma ceylanicum life cycle stages reveals changes in G-protein coupled receptor diversity associated with the onset of parasitism. Int J Parasitol. 2020;50:603-10.

30. Wheeler NJ, Heimark ZW, Airs PM, Mann A, Bartholomay LC, Zamanian M. Genetic and functional diversification of chemosensory pathway receptors in mosquito-borne filarial nematodes. PLoS Biol. 2020;18(6):e3000723.

31. Gang SS, Castelletto ML, Yang E, Ruiz F, Brown TM, Bryant AS, et al. Chemosensory mechanisms of host seeking and infectivity in skinpenetrating nematodes. PNAS. 2020;117:17913-23.

32. Zheng S, Long J, Liu Z, Tao W, Wang D. Identification and evolution of TGF- $\beta$ signaling pathway members in twenty-four animal species and expression in tilapia. Int J Mol Sci. 2018;19:1-21.

33. Patterson GI, Padgett RW. TGF $\beta$-related pathways: roles in Caenorhabditis elegans development. Trends Genet. 2000;16:27-33.

34. Murphy CT, Hu PJ. Insulin/insulin-like growth factor signaling in C. elegans. WormBook. Ed. the C. elegans Research Community; 2013.

35. Gerisch B, Antebi A. Hormonal signals produced by DAF-9/cytochrome P450 regulate $C$. elegans dauer diapause in response to environmental cues. Development. 2004;131:1765-76.

36. Motola DL, Cummins CL, Rottiers V, Sharma KK, Li T, Li Y, et al. Identification of ligands for DAF-12 that govern dauer formation and reproduction in C. elegans. Cell. 2006;124:1209-23.

37. Srinivasan J, Sternberg PW. Pristionchus pacificus: an appropriate fondness for beetles. Nat Methods. 2008;40:1146-7

38. Poinar GOJ. Entomogenous nematodes: a manual and host list of insect-nematode associations. Leiden: Brill; 1975.

39. Li TM, Chen J, Li X, Ding XJ, Wu Y, Zhao LF, et al. Absolute quantification of a steroid hormone that regulates development in Caenorhabditis elegans. Anal Chem. 2013;85:9281-7.

40. Van Megen H, Van Den Elsen S, Holterman M, Karssen G, Mooyman $\mathrm{P}$, Bongers $\mathrm{T}$, et al. A phylogenetic tree of nematodes based on about 
1200 full-length small subunit ribosomal DNA sequences. Nematology. 2009;11:927-50.

41. Grant W, Viney M. The dauer phenomenon. In: Perry RN, Wharton D, editors. Molecular and physiological basis of nematode survival. 1st ed. Cambridge: CAB International; 2011. p. 311

42. Viney ME. How did parasitic worms evolve? BioEssays. 2009;31:496-9.

43. Anderson RC. The superfamily Trichostrongyloidea. In: Nematode parasites of vertebrates: their development and transmission. New York: CABI Publishing: 2000. p. 671.

44. Hotez P, Hawdon J, Schad GA. Hookworm larval infectivity, arrest and amphiparatenesis: the Caenorhabditis elegans Daf-c paradigm. Parasitol Today. 1993;9:23-6.

45. Moens M, Perry RN. Migratory plant endoparasitic nematodes: a group rich in contrasts and divergence. Annu Rev Phytopathol. 2009;47:313-32.

46. Golden JW, Riddle DL. A pheromone influences larval development in the nematode Caenorhabditis elegans. Science. 1982;218:578-80.

47. Golden JW, Riddle DL. The Caenorhabditis elegans dauer larva: developmental effects of pheromone, food, and temperature. Dev Biol. 1984;102:368-78.

48. Butcher RA, Fujita M, Schroeder FC, Clardy J. Small-molecule pheromones that control dauer development in Caenorhabditis elegans. Nat Chem Biol. 2007;3:420-2.

49. Butcher RA. Small-molecule pheromones and hormones controlling nematode development. Nat Chem Biol. 2017;13:577-86.

50. Jeong PY, Jung M, Yim YH, Kim H, Park M, Hong E, et al. Chemical structure and biological activity of the Caenorhabditis elegans dauerinducing pheromone. Nature. 2005;433:541-5.

51. Pungaliya C, Srinivasan J, Fox BW, Malik RU, Ludewig AH, Sternberg PW, et al. A shortcut to identifying small molecule signals that regulate behavior and development in Caenorhabditis elegans. PNAS. 2009;106:7708-13.

52. von Reuss SH, Bose N, Srinivasan J, Yim JJ, Judkins JC, Sternberg PW, et al. Comparative metabolomics reveals biogenesis of ascarosides, a modular library of small-molecule signals in C. elegans. J Am Chem Soc. 2012;134:1817-24.

53. Kim K, Sato K, Shibuya M, Zeiger DM, Butcher RA, Ragains JR, et al. Two chemoreceptors mediate developmental effects of dauer pheromone in C. elegans. Science. 2009;326:994-8.

54. McGrath PT, Xu Y, Ailion M, Garrison JL, Butcher RA, Bargmann CI. Parallel evolution of domesticated Caenorhabditis species targets pheromone receptor genes. Nature. 2012;477:321-5.

55. Park D, O'Doherty I, Somvanshi RK, Bethke A, Schroeder FC, Kumar $\mathrm{U}$, et al. Interaction of structure-specific and promiscuous G-proteincoupled receptors mediates small-molecule signaling in Caenorhabditis elegans. PNAS. 2012;109:9917-22.

56. Bargmann $\mathrm{Cl}$. Chemosensation in C. elegans. WormBook. Ed. the $\mathrm{C}$. elegans Research Community; 2006.

57. Ludewig AH, Schroeder FC. Ascaroside signaling in C. elegans. Wormbook. Ed. the C. elegans Research Community. 2013.

58. Birnby DA, Link EM, Vowels JJ, Tian H, Colacurcio PL, Thomas JH. A transmembrane guanylyl cyclase (DAF-11) and Hsp90 (DAF-21) regulate a common set of chemosensory behaviors in Caenorhabditis elegans. Genetics. 2000;155:85-104.

59. Zheng S, Chiu H, Boudreau J, Papanicolaou T, Bendena W, Chin-Sang I. A functional study of all 40 Caenorhabditis elegans insulin-like peptides. J Biol Chem. 2018:293:16912-22.

60. Paradis S, Ruvkun G. Caenorhabditis elegans Akt/PKB transduces insulin receptor-like signals from AGE-1 PI3 kinase to the DAF-16 transcription factor. Genes Dev. 1998;12:2488-98.

61. Morris JZ, Tissenbaum HA, Ruvkun G. A phosphatidylinositol-3-OH kinase family member regulating longevity and diapause in Caenorhabditis elegans. Nature. 1996;382:536-9.

62. Paradis S, Ailion M, Toker A, Thomas JH, Ruvkun G. A PDK1 homolog is necessary and sufficient to transduce AGE-1 PI3 kinase signals that regulate diapause in Caenorhabditis elegans. Genes Dev. 1999:13:1438-52.

63. Brunet A, Bonni A, Zigmond MJ, Lin MZ, Juo P, Hu LS, et al. Akt promotes cell survival by phosphorylating and inhibiting a forkhead transcription factor. Cell. 1999;96:857-68.
64. Kaplan REW, Webster AK, Chitrakar R, Dent JA, Baugh LR. Food perception without ingestion leads to metabolic changes and irreversible developmental arrest in C. elegans. BMC Biol. 2018;16:1-16.

65. Tissenbaum HA, Hawdon J, Perregaux M, Hotez P, Guarente L, Ruvkun G. A common muscarinic pathway for diapause recovery in the distantly related nematode species Caenorhabditis elegans and Ancylostoma caninum. PNAS. 2000;97:460-5.

66. Ailion $\mathrm{M}$, Thomas JH. Dauer formation induced by high temperatures in Caenorhabditis elegans. Genetics. 2000:156:1047-67.

67. Hobert O, Mori I, Yamashita Y, Honda H, Ohshima Y, Liu Y, et al. Regulation of interneuron function in the C. elegans thermoregulatory pathway by the ttx-3 LIM homeobox gene. Neuron. 1997;19:345-57.

68. Li C, Kim K. Neuropeptides. Wormbook. Ed. the C. elegans Research Community; 2008.

69. Lee JS, Shih PY, Schaedel ON, Quintero-Cadena P, Rogers AK, Sternberg PW. FMRFamide-like peptides expand the behavioral repertoire of a densely connected nervous system. PNAS. 2017;114:E10726-35.

70. McCoy CJ, Atkinson LE, Zamanian M, McVeigh P, Day TA, Kimber MJ, et al. New insights into the FLPergic complements of parasitic nematodes: informing deorphanisation approaches. EuPA. 2014;3:262-72.

71. Kubiak TM, Larsen MJ, Davis JP, Zantello MR, Bowman JW. AF2 interaction with Ascaris suum body wall muscle membranes involves G-protein activation. Biochem Biophys Res Commun. 2003;301:456-9.

72. Ren P, Lim C-S, Johnsen R, Albert PS, Pilgrim D, Riddle DL. Control of $C$. elegans larval development by neuronal expression of a TGF- $\beta$ homolog. Science. 1996;274:1389-91.

73. Schackwitz WS, Inoue T, Thomas JH. Chemosensory neurons function in parallel to mediate a pheromone response in C. elegans. Neuron. 1996;17:719-28.

74. Georgi LL, Albert PS, Riddle DL. daf-1, a C. elegans gene controlling dauer larva development, encodes a novel receptor protein kinase. Cell. 1990;61:635-45.

75. Estevez M, Attisano L, Wrana JL, Albert PS, Massagué J, Riddle DL. The daf-4 gene encodes a bone morphogenetic protein receptor controlling C. elegans dauer larva development. Nat Lett. 1993;363:644-9.

76. Savage-Dunn, C. TGF- $\beta$ signaling. WormBook, Ed. The C. elegans Research Community; 2005.

77. Gerisch B, Weitzel C, Kober-Eisermann C, Rottiers V, Antebi A. A hormonal signaling pathway influencing C. elegans metabolism, reproductive development, and life span. Dev Cell. 2001;1:841-51.

78. Li J, Brown G, Ailion M, Lee S, Thomas JH. NCR-1 and NCR-2, the $C$. elegans homologs of the human Niemann-Pick type C1 disease protein, function upstream of DAF-9 in the dauer formation pathways. Development. 2004;131:5741-52.

79. Rottiers V, Motola DL, Gerisch B, Cummins CL, Nishiwaki K, Mangelsdorf $D J$, et al. Hormonal control of $C$. elegans dauer formation and life span by a Rieske-like oxygenase. Dev Cell. 2006;10:473-82.

80. Wollam J, Magner DB, Magomedova L, Rass E, Shen Y, Rottiers V, et al. A novel 3-hydroxysteroid dehydrogenase that regulates reproductive development and longevity. PLoS Biol. 2012;10:19-21.

81. Jia K, Albert PS, Riddle DL. DAF-9, a cytochrome P450 regulating C. elegans larval development and adult longevity. Development. 2002:129.221-31.

82. Mahanti P, Bose N, Bethke A, Judkins JC, Wollam J, Dumas KJ, et al. Comparative metabolomics reveals endogenous ligands of DAF-12, a nuclear hormone receptor, regulating C. elegans development and lifespan. Cell Metab. 2014;19:73-83.

83. Bethke A, Fielenbach N, Wang Z, Mangelsdorf DJ, Antebi A. Nuclear hormone receptor regulation of microRNAs controls developmental progression. Science. 2009;324:95-8.

84. Ludewig AH, Kober-eisermann C, Weitzel C, Bethke A, Neubert K, Gerisch B, et al. A novel nuclear receptor/coregulator complex controls. Genes Dev. 2004;18:2120-33.

85. Howe KL, Bolt BJ, Shafie M, Kersey P, Berriman M. WormBase ParaSite-a comprehensive resource for helminth genomics. Mol Biochem Parasitol. 2017:215:2-10.

86. Li X, Massey HC, Nolan TJ, Schad GA, Kraus K, Sundaram M, et al. Successful transgenesis of the parasitic nematode Strongyloides stercoralis requires endogenous non-coding control elements. Int J Parasitol. 2006:36:671-9. 
87. Urwin PE, Lilley CJ, Atkinson HJ. Ingestion of double-stranded RNA by preparasitic larvae cyst nematodes leads to RNA interference. Mol Plant Microbe Interact. 2002;15:747-52.

88. Ma G, Wang T, Korhonen PK, Nie S, Reid GE, Stroehlein AJ, et al. Comparative bioinformatic analysis suggests that specific dauer-like signalling pathway components regulate Toxocara canis development and migration in the mammalian host. Parasites Vectors. 2019:12:1-10.

89. Gomez-Escobar N, Gregory WF, Maizels RM. Identification of tgh-2, a filarial nematode homolog of Caenorhabditis elegans daf-7 and human transforming growth factor $\beta$, expressed in microfilarial and adult stages of Brugia malayi. Infect Immun. 2000;68:6402-10.

90. Gilabert A, Curran DM, Harvey SC, Wasmuth JD. Expanding the view on the evolution of the nematode dauer signalling pathways: refinement through gene gain and pathway co-option. BMC Genom. 2016;17:1-10.

91. Zhu XQ, Korhonen PK, Cai H, Young ND, Nejsum P, Von SamsonHimmelstjerna G, et al. Genetic blueprint of the zoonotic pathogen Toxocara canis. Nat Commun. 2015;6:6145.

92. Long T, Alberich M, André F, Menez C, Prichard RK, Lespine A. The development of the dog heartworm is highly sensitive to sterols which activate the orthologue of the nuclear receptor DAF-12. Sci Rep. 2020;10:1-13

93. Hawdon JM, Datu B. The second messenger cyclic GMP mediates activation in Ancylostoma caninum infective larvae. Int J Parasitol. 2003;33:787-93.

94. Datu BJD, Loukas A, Cantacessi C, O'Donoghue P, Gasser RB. Investigation of the regulation of transcriptional changes in Ancylostoma caninum larvae following serum activation, with a focus on the insulin-like signalling pathway. Vet Parasitol. 2009;159:139-48.

95. Huang SCC, Chan DTY, Smyth DJ, Ball G, Gounaris K, Selkirk ME. Activation of Nippostrongylus brasiliensis infective larvae is regulated by a pathway distinct from the hookworm Ancylostoma caninum. Int J Parasitol. 2010;40:1619-28.

96. Mohandas N, Hu M, Stroehlein AJ, Young ND, Sternberg PW, Lok JB, et al. Reconstruction of the insulin-like signalling pathway of Haemonchus contortus. Parasites Vectors. 2016:9:1-10.

97. Brand A, Hawdon JM. Phosphoinositide-3-OH-kinase inhibitor LY294002 prevents activation of Ancylostoma caninum and Ancylostoma ceylanicum third-stage infective larvae. Int J Parasitol. 2004;34:909-14.

98. Li FC, Gasser RB, Lok JB, Korhonen PK, Wang YF, Yin FY, et al. Exploring the role of two interacting phosphoinositide 3-kinases of Haemonchus contortus. Parasites Vectors. 2014;7:1-12.

99. Li FC, Gasser RB, Lok JB, Korhonen PK, He L, Da DW, et al. Molecular characterization of the Haemonchus contortus phosphoinositidedependent protein kinase-1 gene (Hc-pdk-1). Parasites Vectors. 2016:9:1-9.

100. Di W, Gasser RB, Zhou C, Zhou Y. A serine/threonine-specific protein kinase of Haemonchus contortus with a role in the development. FASEB. 2019;00:1-12

101. Yan B, Sun W, Yan L, Zhang L, Zheng Y, Zeng Y, et al. Structural and functional characterisation of FOXO/Acan-DAF-16 from the parasitic nematode Angiostrongylus cantonensis. Acta Trop. 2016;164:125-36.

102. Brand AM, Varghese G, Majewski W, Hawdon JM. Identification of a DAF-7 ortholog from the hookworm Ancylostoma caninum. Int J Parasitol. 2005;35:1489-98.

103. Freitas TC, Arasu P. Cloning and characterisation of genes encoding two transforming growth factor- $\beta$-like ligands from the hookworm, Ancylostoma caninum. Int J Parasitol. 2005;35:1477-87.

104. McSorley HJ, Grainger JR, Harcus Y, Murray J, Nisbet AJ, Knox DP, et al. daf-7-related TGF- $\beta$ homologues from Trichostrongyloid nematodes show contrasting life-cycle expression patterns. Parasitology. 2010;137:159-71.

105. Ayoade KO, Carranza FR, Cho WH, Wang Z, Kliewer SA, Mangelsdorf DJ, et al. Dafachronic acid and temperature regulate canonical dauer pathways during Nippostrongylus brasiliensis infectious larvae activation. Parasites Vectors. 2020;13:1-15.

106. Di W, Liu L, Zhang T, Li F, He L, Wang C, et al. A DAF-3 co-Smad molecule functions in Haemonchus contortus development. Parasites Vectors. 2019;12:609.

107. He L, Gasser RB, Li T, Di W, Li F, Zhang H, et al. A TGF- $\beta$ type II receptor that associates with developmental transition in Haemonchus contortus in vitro. PLoS Negl Trop Dis. 2019;13:1-18.
108. Lok JB. Signaling in parasitic nematodes: physicochemical communication between host and parasite and endogenous molecular transduction pathways governing worm development and survival. Curr Clin Microbiol Rep. 2016;3:186-97.

109. Wang Z, Zhou XE, Motola DL, Gao X, Suino-Powell K, Conneely A, et al. Identification of the nuclear receptor DAF-12 as a therapeutic target in parasitic nematodes. PNAS. 2009;106:9138-43.

110. Zhi X, Zhou XE, Melcher K, Motola DL, Gelmedin V, Hawdon J, et al. Structural conservation of ligand binding reveals a bile acid-like signaling pathway in nematodes. J Biol Chem. 2012;287:4894-903.

111. Ma G, Wang T, Korhonen PK, Young ND, Nie S, Ang CS, et al. Dafachronic acid promotes larval development in Haemonchus contortus by modulating dauer signalling and lipid metabolism. PLoS Pathog. 2019;15:1-20.

112. Hawdon JT, Schad GA. Serum-stimulated feeding in vitro by third-stage infective larvae of the canine hookworm Ancylostoma caninum. J Parasitol. 1990;76:394-8.

113. Stasiuk SJ, Scott MJ, Grant WN. Developmental plasticity and the evolution of parasitism in an unusual nematode, Parastrongyloides trichosuri. EvoDevo. 2012;3:1-14.

114. Zhao L, Zhang S, Wei W, Hao H, Zhang B, Butcher RA, et al. Chemical signals synchronize the life cycles of a plant-parasitic nematode and its vector beetle. Curr Biol. 2013;23:2038-43.

115. Zhang W, Li Y, Pan L, Wang X, Feng Y, Zhang X. Pine chemical volatiles promote dauer recovery of a pine parasitic nematode, Bursaphelenchus xylophilus. Parasitology. 2019;147:1-8.

116. Wu Y, Wickham JD, Zhao L, Sun J. $\mathrm{CO}_{2}$ drives the pine wood nematode off its insect vector. Curr Biol. 2019;29:R619-20.

117. Tanaka SE, Aikawa T, Takeuchi-Kaneko Y, Fukuda K, Kanzaki N. Artificial induction of third-stage dispersal juveniles of Bursaphelenchus xylophiI us using newly established inbred lines. PLOS ONE. 2017:12:1-16.

118. Stoltzfus JD, Bart SM, Lok JB. cGMP and NHR signaling co-regulate expression of insulin-like peptides and developmental activation of infective larvae in Strongyloides stercoralis. PLoS Pathog. 2014;10(7):e1004235.

119. Massey HC, Ball CC, Lok JB. PCR amplification of putative gpa-2 and gpa-3 orthologs from the $(\mathrm{A}+\mathrm{T})$-rich genome of Strongyloides stercoralis. Int J Parasitol. 2001;31:377-83.

120. Bryant AS, Ruiz F, Gang SS, Castelletto ML, Lopez JB, Hallem EA. A critical role for thermosensation in host seeking by skin-penetrating nematodes. Curr Biol. 2018;28:2338-47.

121. Stoltzfus JD, Massey HC, Nolan TJ, Griffith SD, Lok JB. Strongyloides stercoralis age-1: a potential regulator of infective larval development in a parasitic nematode. PLoS ONE. 2012;7:1-11.

122. Tanaka SE, Dayi M, Maeda Y, Tsai IJ, Tanaka R, Bligh M, et al. Stagespecific transcriptome of Bursaphelenchus xylophilus reveals temporal regulation of effector genes and roles of the dauer-like stages in the lifecycle. Sci Rep. 2019;9:1-13.

123. Massey HC, Bhopale MK, Li X, Castelletto M, Lok JB. The fork head transcription factor FKTF-1b from Strongyloides stercoralis restores DAF-16 developmental function to mutant Caenorhabditis elegans. Int J Parasitol. 2006:36:347-52.

124. Crook M, Thompson FJ, Grant WN, Viney ME. daf-7 and the development of Strongyloides ratti and Parastrongyloides trichosuri. Mol Biochem Parasitol. 2005;139:213-23.

125. Massey HC, Castelletto ML, Bhopale VM, Schad GA, Lok JB. Sst-tgh-1 from Strongyloides stercoralis encodes a proposed ortholog of daf-7 in Caenorhabditis elegans. Mol Biochem Parasitol. 2005;142:116-20.

126. Albarqi MMY, Stoltzfus JD, Pilgrim AA, Nolan TJ, Wang Z, Kliewer SA, et al. Regulation of life cycle checkpoints and developmental activation of infective larvae in Strongyloides stercoralis by dafachronic acid. PLoS Pathog. 2016;12:1-20.

127. Wang DD, Cheng XY, Wang YS, Pan HY, Xie BY. Characterization and expression of daf- 9 and daf-12 genes in the pinewood nematode, Bursaphelenchus xylophilus. For Pathol. 2013;43:144-52.

128. Ogawa A, Streit A, Antebi A, Sommer RJ. A conserved endocrine mechanism controls the formation of dauer and infective larvae in nematodes. Curr Biol. 2009;19:67-71.

129. Dulovic A, Streit A. RNAi-mediated knockdown of daf- 12 in the model parasitic nematode Strongyloides ratti. PLoS Pathog. 2019:15:1-25. 
130. Jones JT, Haegeman A, Danchin EGJ, Gaur HS, Helder J, Jones MGK, et al. Top 10 plant-parasitic nematodes in molecular plant pathology. Mol Plant Pathol. 2013;14:946-61.

131. Rogers WP, Sommerville RI. The infective stage of nematode parasites and its significance in parasitism. Adv Parasitol. 1963;1:109-77.

132. Tarjan AC. Longevity of Radopholus similis (Cobb) in host-free soil. Nematologica. 1961:6:170-5.

133. Bird AF, Buttrose MS. Ultrastructural changes in the nematode Anguina tritici associated with anhydrobiosis. J Ultrasructure Res. 1974;48:177-89.

134. Hunt DJ, Luc M, Manzanilla-López RH. Plant parasitic nematodes in subtropical and tropical agriculture. In: Luc M, Sikora RA, Bridge J, editors. Identification, morphology and biology of plant parasitic nematodes. 2nd ed. Wallingford: CABI publishing; 2005. p. 11-52.

135. Yang D, Chen C, Liu Q, Jian H. Comparative analysis of pre- and postparasitic transcriptomes and mining pioneer effectors of Heterodera avenae. Cell Biosci. 2017;7:1-18.

136. Proudfoot L, Kusel JR, Smith HV, Harnett W, Worms MJ, Kennedy MW. Rapid changes in the surface of parasitic nematodes during transition from pre- to post-parasitic forms. Parasitology. 1993;107:107-17.

137. Akhkha A, Kusel J, Kennedy M, Curtis R. Effects of phytohormones on the surfaces of plant-parasitic nematodes. Parasitology. 2002;125:165-75

138. McCarter JP, Mitreva MD, Martin J, Dante M, Wylie T, Rao U, et al. Analysis and functional classification of transcripts from the nematode Meloidogyne incognita. Genome Biol. 2003:4:1-19.

139. Popeijus H, Blok VC, Cardle L, Bakker E, Phillips MS, Helder J, et al. Analysis of genes expressed in second stage juveniles of the potato cyst nematodes Globodera rostochiensis and G. pallida using the expressed sequence tag approach. Nematology. 2000;2:567-74.

140. Lu C-J, Tian B-Y, Cao Y, Zou C-G, Zhang K-Q. Nuclear receptor nhr-48 is required for pathogenicity of the second stage (J2) of the plant parasite Meloidogyne incognita. Sci Rep. 2016:6:1-12.

141. Schroeder NE, MacGuidwin AE. Behavioural quiescence reduces the penetration and toxicity of exogenous compounds in second-stage juveniles of Heterodera glycines. Nematology. 2010;12:277-87.

142. Sikder MM, Vestergård M. Impacts of root metabolites on soil nematodes. Front Plant Sci. 2020;10:1-18.

143. Perry RN, Clarke AJ. Hatching mechanisms of nematodes. Parasitology. 1981:83:435-49.

144. Masamune T, Anetai M, Takasugi M, Katsui N. Isolation of a natural hatching stimulus, glycinoeclepin A, for the soybean cyst nematode. Nature. 1982;297:495-6.

145. Schenk H, Driessen RAJ, De Gelder R. Elucidation of the structure of solanoeclepin A, a natural hatching factor of potato and tomato cyst nematodes, by single-crystal X-ray diffraction. Croat Chem Acta. 1999;72:593-606.

146. Sakata I, Kushida A, Tanino K. The hatching-stimulation activity of solanoeclepin A toward the eggs of Globodera (Tylenchida: Heteroderidae) species. Appl Entomol Zool. 2020;56(1):51-7.

147. Huang $X$, Xu CL, Yang SH, Li JY, Le WH, Zhang ZX, et al. Life-stage specific transcriptomes of a migratory endoparasitic plant nematode, Radopholus similis elucidate a different parasitic and life strategy of plant parasitic nematodes. Sci Rep. 2019;9:1-11.

148. Opperman CH, Bird DM, Williamson VM, Rokhsar DS, Burke M, Cohn $J$, et al. Sequence and genetic map of Meloidogyne hapla: a compact nematode genome for plant parasitism. PNAS. 2008;105:14802-7.

149. Shivakumara TN, Dutta TK, Chaudhary S, Von Reuss SH, Williamson VM Rao U. Homologs of Caenorhabditis elegans chemosensory genes have roles in behavior and chemotaxis in the root-knot nematode Meloidogyne incognita. Mol Plant Microbe Interact. 2019;31:876-87.

150. Laloum Y, Ngala B, lanszen M, Boulogne I, Plasson C, Fournet S, et al. A novel in vitro tool to study cyst nematode chemotaxis. Front Plant Sci. 2020:11:1-7.

151. Kimber MJ, McKinney S, McMaster S, Day TA, Fleming CC, Maule AG. flp gene disruption in a parasitic nematode reveals motor dysfunction and unusual neuronal sensitivity to RNA interference. FASEB. 2007;21:1233-43.

152. Dong L, Li X, Huang C, Lu Q, Li B, Yao Y, et al. Reduced Meloidogyne incognita infection of tomato in the presence of castor and the involvement of fatty acids. Sci Hortic. 2018;237:169-75.
153. Dong L, Li X, Huang L, Gao Y, Zhong L, Zheng Y, et al. Lauric acid in crown daisy root exudate potently regulates root-knot nematode chemotaxis and disrupts Mi-flp-18 expression to block infection. J Exp Bot. 2014;65:131-41.

154. Kumari C, Dutta TK, Chaudhary S, Banakar P, Papolu PK, Rao U. Molecular characterization of FMRFamide-like peptides in Meloidogyne graminicola and analysis of their knockdown effect on nematode infectivity. Gene. 2017;619:50-60.

155. Cox DE, Dyer S, Weir R, Cheseto X, Sturrock M, Coyne D, et al. ABC transporter genes $A B C-C 6$ and $A B C-G 33$ alter plant-microbe-parasite interactions in the rhizosphere. Sci Rep. 2019;9:1-13.

156. Basso MF, Lourenço-tessutti IT, Mendes RAG, Moreira Pinto CE, Bournaud C, Gillet F-X, et al. MiDaf16-like and MiSkn 1-like gene families are reliable targets to develop biotechnological tools for the control and management of Meloidogyne incognita. Sci Rep. 2020;10:1-13.

157. Gillet F-X, Bournaud C, Antonino de Souza Júnior JD, Grossi-de-Sa MF. Plant-parasitic nematodes: towards understanding molecular players in stress responses. Ann Bot. 2017;119:775-89.

158. Palomares-Rius JE, Jones JT, Cock PJ, Castillo P, Blok VC. Activation of hatching in diapaused and quiescent Globodera pallida. Parasitology. 2013;140:445-54

159. Elling AA, Mitreva M, Recknor J, Gai X, Martin J, Maier TR, et al. Divergent evolution of arrested development in the dauer stage of Caenorhabditis elegans and the infective stage of Heterodera glycines. Genome Biol. 2007:8:1-19.

160. Bird DM, Jones JT, Opperman CH, Kikuchi T, Danchin TGJ. Signatures of adaptation to plant parasitism in nematode genomes. Parasitology. 2015;142:S71-84.

161. Sargison ND, Wilson DJ, Bartley DJ, Penny CD, Jackson F. Haemonchosis and teladorsagiosis in a Scottish sheep flock putatively associated with the overwintering of hypobiotic fourth stage larvae. Vet Parasitol. 2007;147:326-31.

162. Palomares-Rius JE, Hedley P, Cock PJA, Morris JA, Jones JT, Blok VC. Gene expression changes in diapause or quiescent potato cyst nematode, Globodera pallida, eggs after hydration or exposure to tomato root diffusate. PeerJ. 2016:4:1-23.

163. Ma G, Wang T, Korhonen PK, Hofmann A, Sternberg PW, Young $\mathrm{ND}$, et al. Elucidating the molecular and developmental biology of parasitic nematodes: moving to a multiomics paradigm. Adv Parasitol. 2020;108:175-229.

164. Wang Z. Nuclear receptor controls nematode metabolism and development: insight into man's nemesis, the conqueror worm (Doctoral dissertation). University of Texas Southwestern Medical Center, Dallas, USA. 2010.

165. Byrne JT, Maher NJ, Jones PW. Comparative responses of Globodera rostochiensis and G. pallida to hatching chemicals. J Nematol. 2001;33:195-202.

166. Ma G, Wang T, Korhonen PK, Stroehlein AJ, Young ND, Gasser RB. Dauer signalling pathway model for Haemonchus contortus. Parasites Vectors. 2019;12:1-11

\section{Publisher's Note}

Springer Nature remains neutral with regard to jurisdictional claims in published maps and institutional affiliations.

Ready to submit your research? Choose BMC and benefit from:

- fast, convenient online submission

- thorough peer review by experienced researchers in your field

- rapid publication on acceptance

- support for research data, including large and complex data types

- gold Open Access which fosters wider collaboration and increased citations

- maximum visibility for your research: over 100M website views per year

At BMC, research is always in progress.

Learn more biomedcentral.com/submissions 